\title{
NADPH Oxidase 1 Mediates $\alpha$-Synucleinopathy in Parkinson's Disease
}

\author{
Ana Clara Cristóvão, ${ }^{1,2,3}$ Subhrangshu Guhathakurta, ${ }^{1}$ Eugene Bok, ${ }^{1}$ Goun Je, ${ }^{1}$ Seung Don Yoo, ${ }^{1,5}$ Dong-Hee Choi, ${ }^{4}$ \\ and Yoon-Seong Kim ${ }^{1}$ \\ ${ }^{1}$ Burnett School of Biomedical Sciences, College of Medicine, University of Central Florida, Orlando, Florida 32827, ${ }^{2}$ Health Sciences Research Center, \\ University of Beira Interior, Covilhã 6200-506, Portugal, ${ }^{3}$ Experimental Biology and Biomedicine, Center for Neuroscience and Cell Biology, University of \\ Coimbra, Coimbra 3400-516, Portugal, ${ }^{4}$ Department of Medical Science, Konkuk University School of Medicine and Center for Neuroscience, SMART \\ Institute of Advanced Biomedical Science, Konkuk University, Seoul 143-701, South Korea, and ${ }^{5}$ Department of Physical Medicine and Rehabilitation, \\ School of Medicine, Kyung Hee University, Seoul 130-701, Republic of Korea
}

Accumulation of misfolded $\alpha$-synuclein is the pathological hallmark of Parkinson's disease (PD). Nevertheless, little is known about the mechanism contributing to $\alpha$-synuclein aggregation and its further toxicity to dopaminergic neurons. Since oxidative stress can increase the expression and aggregation levels of $\alpha$-synuclein, NADPH oxidases (Noxs), which are responsible for reactive oxygen species generation, could be major players in $\alpha$-synucleinopathy. Previously, we demonstrated that Noxl is expressed in dopaminergic neurons of the PD animal models as well as postmortem brain tissue of PD patients, and is responsible for oxidative stress and subsequent neuronal degeneration. Here, using paraquat (PQ)-based in vitro and in vivo PD models, we show that Nox1 has a crucial role in modulating the behavior of $\alpha$-synuclein expression and aggregation in dopaminergic neurons.

We observed in differentiated human dopaminergic cells that Nox1 and $\alpha$-synuclein expressions are increased under PQ exposure. Nox1 knockdown significantly reduced both $\alpha$-synuclein expression and aggregation, supporting the role of Nox1 in this process. Furthermore, in rats exposed to $\mathrm{PQ}$, the selective knockdown of Nox1 in the substantia nigra, using adeno-associated virus encoding Nox1-specific shRNA, largely attenuated the PQ-mediated increase of $\alpha$-synuclein and ubiquitin expression levels as well as $\alpha$-synuclein aggregates (proteinase K resistant) and A11 oligomers. Significant reductions in oxidative stress level and dopaminergic neuronal loss were also observed. Our data reveal a new mechanism by which $\alpha$-synuclein becomes a neuropathologic protein through Nox1-mediated oxidative stress. This finding may be used to generate new therapeutic interventions that slower the rate of $\alpha$-synuclein aggregation and the progression of PD pathogenesis.

\section{Introduction}

Despite there being numerous studies performed to decipher the pathogenesis of Parkinson disease (PD), the exact cause rendering this pathology remains unknown, indicating a multifactorial etiology behind the disease. To understand the mechanism of neuronal death occurring in $\mathrm{PD}$, it is important to solve the enigma of plausible interaction between different factors, like oxidative stress and genetic factors, which may culminate in dopaminergic neurodegeneration.

\footnotetext{
Received May 9, 2012; revised July 31, 2012; accepted Aug. 14, 2012.

Author contributions: A.C.C. and Y.-S.K. designed research; A.C.C., S.G., S.D.Y., D.-H.C., and Y.-S.K. performed research; E.B., G.J., and D.-H.C. contributed unpublished reagents/analytic tools; A.C.C. and Y.-S.K. analyzed data; A.C.C., S.G., and Y.-S.K. wrote the paper.

This work was supported by the National Institutes of Health Grant R01 NS062827 (Y.-S.K.) and Michael J. Fox Foundation Grant Target Validation 2009 (Y.-S.K.). A.C.C. was supported by the Portuguese Foundation for Science and Technology (SFRH/BD/15889/2005 and SFRH/BPD/69643/2010). D.-H.C. was supported by Basic Science Research Program through the National Research Foundation of Korea funded by the Ministry of Education, Science, and Technology (2011-0017016).

Correspondence should be addressed to Dr. Yoon-Seong Kim, Assistant Professor, University of Central Florida, Burnett School of Biomedical Sciences, College of Medicine, 6900 Lake Nona Boulevard, Orlando, FL 32827. E-mail: Yoon-Seong.Kim@ucf.edu.

DOI:10.1523/JNEUROSCI.2246-12.2012

Copyright $\odot 2012$ the authors $\quad 0270-6474 / 12 / 3214465-13 \$ 15.00 / 0$
}

$\alpha$-Synuclein, the principal component of Lewy bodies, has been reported as a cause of PD (Beyer et al., 2009; Cookson, 2009). The encoding gene of $\alpha$-synuclein, $S N C A$, is the first gene where a strong correlation between its functional mutations and familial form of PD was demonstrated (Polymeropoulos et al., 1997; Krüger et al., 1998; Zarranz et al., 2004). While the molecular mechanism underlying its toxic effects on the nigrostriatal system is largely unknown, the aberrant expression and aggregation of $\alpha$-synuclein have been considered as potential causes involved in neuronal toxicity (Vekrellis et al., 2011).

Evidence suggested that paraquat (PQ) is a specific neurotoxin for dopaminergic neurodegeneration in the substantia nigra (SN) (Brown et al., 2006; Gatto et al., 2010), and the structure of PQ suggests that increased oxidative stress might be the reason of its toxicity. The SN of PD patients' postmortem brain tissues showed high oxidative stress with an increase in lipid peroxidation (Dexter et al., 1989), oxidative damages in DNA (Zhang et al., 1999) and protein (Alam et al., 1997), and decreased glutathione levels (Sofic et al., 1992). Evidence has demonstrated that the NADPH oxidase (Nox) complexes also play a role in generating reactive oxygen species (ROS) beside mitochondria, and are implicated in several pathologic conditions in 
CNS (Sorce and Krause, 2009). Our previous results showed that Nox1, an isoform of the Nox family, has a role in PQ-mediated dopaminergic neuronal cell death both in vivo and in cell cultures (Cristóvão et al., 2009). Recently, we have demonstrated that Nox1/Rac1 is activated in dopaminergic neurons following 6-hydroxydopamine (6-OHDA) treatment as well, causing oxidative stress and consequential neuronal death (Choi et al., 2012). Since oxidative stress is generally considered as a factor affecting $\alpha$-synuclein aggregation (Krishnan et al., 2003), PQmediated oxidative stress was also shown to increase $\alpha$-synuclein aggregation and expression levels in the $\mathrm{SN}$ of mice (ManningBog et al., 2002). Halting the expression levels of $\alpha$-synuclein in a mouse model of PD was shown to be beneficial with reduced progression of neurodegeneration (Nuber et al., 2008). Understanding how $\alpha$-synuclein expression and aggregation is regulated will provide us with targets that ultimately may be used to control and reduce the progression of certain aspects of the disease phenotype.

In the current study, we have investigated the effect of Nox1derived ROS on the expression and aggregation of $\alpha$-synuclein in the $\mathrm{SN}$ of rats exposed to PQ. We demonstrated that PQ-treated rats show noticeable $\alpha$-synuclein increased expression and aggregation, which were clearly reduced in Noxl knockdown.

\section{Materials and Methods}

\section{Cell cultures}

ReNcell VM culture method. For the in vitro experiments on human dopaminergic neurons, we have used human mesencephalic neuronal progenitor cell line available from Millipore (catalog number SCC008). The specialty of these cells is that they are isolated from fetal human ventral mesencephalic region and subsequently immortalized by introduction of v-myc. The cells can readily differentiate into dopaminergic neurons upon withdrawal of growth factors (Millipore). We have followed the culture method as indicated by the company with little modifications. Briefly, the cells were allowed to grow on laminin-coated $(20 \mu \mathrm{g} / \mathrm{ml})$ dishes in DMEM/F12-containing medium with B27 supplement, glutamax, heparin $(10 \mathrm{U} / \mathrm{ml})$, and gentamicin $(50 \mu \mathrm{g} / \mathrm{ml})$. This medium is called maintenance medium. Cell division was allowed by addition of the two growth factors in the medium viz., basic fibroblast growth factor (bFGF) and epidermal growth factor (EGF), both at a concentration of $20 \mathrm{ng} / \mathrm{ml}$. To induce differentiation, both growth factors were removed from the media and the cells were allowed to differentiate for $14 \mathrm{~d}$ with changing medium every alternate day before harvesting or any treatment. After differentiation, cells were treated with $800 \mu \mathrm{M}$ or $1000 \mu \mathrm{M}$ PQ for 8 and $24 \mathrm{~h}$.

Immortalized rat mesencephalic dopaminergic cell (N27 cells) culture. The N27 cells were grown in RPMI 1640 medium containing 10\% fetal bovine serum (FBS), $100 \mathrm{U}$ penicillin, and $50 \mu \mathrm{g} / \mathrm{ml}$ streptomycin, in a humidified atmosphere of $5 \% \mathrm{CO}_{2}$ at $37^{\circ} \mathrm{C}$. $\mathrm{N} 27$ cultures were prepared for experiments by plating the cells on polystyrene tissue culture dishes at a density of $0.5 \times 10^{5}$ cells/well in 24-well culture plates with glass coverslip and at $1.5 \times 10^{5}$ cells/well in 6-well culture plates.

\section{Animals and treatment paradigm}

The experiments were performed on rats, in accordance with the National Institutes for Health Guide for the Care and Use of Laboratory Animals. All procedures were approved by the local Animal Care and Use Committee. Male Wistar rats (8-10 weeks; Charles River) were maintained in a temperature/humidity-controlled environment under a $12 \mathrm{~h}$ light/dark cycle with ad libitum access to food and water. As depicted in Figure $7 A$, each animal received four intraperitoneal injections, separated by $1 \mathrm{~d}$, of either vehicle (saline) or PQ (10 mg/kg body weight; b.w.), according to a previously published dose (Manning-Bog et al., 2002; Harraz et al., 2008; Cristóvão et al., 2009). All animals were weighed at day 1 and 12. In the studies using the paradigm depicted in Figure 7A, 4 weeks before starting PQ intraperitoneal injection, animals were stereotaxically injected with various viral constructs at the right $\mathrm{SN}$ using the following coordinates: mediolateral, +2.0 ; anteroposterior, -5.3 ; dorsoventral, -6.8 . Animals were organized into four groups: vector + vehicle: stereotaxically injected with adeno-associated virus (AAV) particles containing a green fluorescent protein (GFP) vector (vector) and then intraperitoneally injected with saline (vehicle) $(n=10)$; vector + PQ: stereotaxically injected with vector and then intraperitoneally injected with PQ $(n=10)$; shNox1 + PQ: stereotaxically injected with AAV particles harboring Nox1 shRNA and then intraperitoneally injected with PQ $(n=10)$; shNox1 + vehicle: stereotaxically injected with Nox1 shRNA and then intraperitoneally injected with vehicle $(n=8)$. AAV containing GFP vector was used as a negative control. Five days after the last PQ intraperitoneal injection, animals were killed. For Western blot analysis, brains were collected and total protein lysates from SN were prepared. For immunohistochemical analysis, animals were intracardially perfused before collecting the brains.

\section{Construction of shRNA delivery vector U6-CMV-EGFP/pAAV (AAV-Nox1 shRNA) and preparation of rAAV2 containing Nox1 shRNA}

U6 promoter-driven shRNA expression system was established in AAV serotype 2 (AAV2) vector. Enhanced GFP (EGFP) expression is separately controlled by a cytomegalovirus (CMV) promoter as a marker for the transduction efficiency. Rat Noxl shRNA was designed based on the siRNA sequence, which efficiently knocked down Noxl expression in N27 cells (Cristóvão et al., 2009).

The plasmid DNA vector only or AAV-Nox1 shRNA was cotransfected with plasmids pHelper and pAAV-RC to HEK293 AAV cells using a standard calcium phosphate method. After $72 \mathrm{~h}$, the cells were harvested and crude rAAV vector solutions were obtained by repeated freeze/thaw cycles. The cleared crude lysate was then applied on a heparin column. After the total lysate pass through the column, the matrix was washed twice with $25 \mathrm{ml}$ of PBS with low $\mathrm{NaCl}(\mathrm{pH} 7.4,0.1 \mathrm{M} \mathrm{NaCl})$. The virus was then eluted with $15 \mathrm{ml}$ of PBS with high $\mathrm{NaCl}$ (PBS; pH 7.4, $0.4 \mathrm{M} \mathrm{NaCl}$ ). The elute was concentrated to $\sim 1 \mathrm{ml}$ with a Millipore Biomax-100K NMWL filter device (UFV2BHK40) by centrifugation $4000 \mathrm{rpm}, 15-40$ min. To adjust the $\mathrm{NaCl}$ concentration to physiological levels, the filter device was refilled with PBS, $\mathrm{pH}$ 7.4, and the virus was concentrated to 250-300 $\mu$ l. After removal of the virus-containing solution, the membrane of the filter device was washed three times with PBS, pH 7.4, which was added to the main part of the recombinant AAV2. The fractions containing high-titer $\mathrm{rAAV}$ vectors were collected and used for injection into animals. The number of rAAV genome copies was semiquantified by PCR within the CMV promoter region using primers 5'-GACGTCAATA ATGACGTATG-3' and $5^{\prime}$-GGTAATAGCGATGACTAATACG- ${ }^{\prime}$. The final titers were $6.4 \times 10^{11}$ genomes/ $\mu \mathrm{l}$ (rAAV2-vector) and $5.5 \times 10^{11}$ genomes $/ \mu$ l (rAAV2-NOX-1 shRNA). Each animal received $16.5 \times$ $10^{11}$ genomes of the respective rAAV-vector.

\section{Construction of shRNA delivery vector $p L V X-s h R N A 2-z s G r e e n 1 /$} LVX (Lenti-Nox1 shRNA) and preparation of lentivirus containing Nox1 shRNA

The same Nox1 shRNA used for AAV2 construct was cloned into a pLVX-shRNA2 vector containing zsGreen1 (Clontech). To make lentiviral particles, ViraPower Lentiviral Expression System (Invitrogen) was used. The three packaging plasmids pLP1, pLP2, and pLP/VSVG, were individually purified from the mixture based on the pattern of restriction enzyme digestion. pLVX-shRNA2-rNoxl and the three packaging plasmids were cotransfected to Lenti-X 293T cells (Clontech) according to the Xfect transfection reagent protocol (Clontech). For 6-well plates, 8 $\mu \mathrm{g}$ of each plasmid was mixed in a 1:1:1:1 ratio in $100 \mu \mathrm{l}$ of Xfect polymer buffer and then added to the cells. After $48 \mathrm{~h}$, the viral-containing medium was harvested and centrifuged briefly at $500 \times \mathrm{g}$ for $10 \mathrm{~min}$ to remove cellular debris and supernatant recovered and kept at $-80^{\circ} \mathrm{C}$ until used.

\section{Transient transfection of $\alpha$-synuclein tagged with FLAG (N} terminal) and $M y c$ (C terminal)

Human $\alpha$-synuclein was cloned into the p3xFLAG-myc-CMV-23 expression vector (Sigma) for $\mathrm{N}$ - and C-terminal tagging with FLAG and 

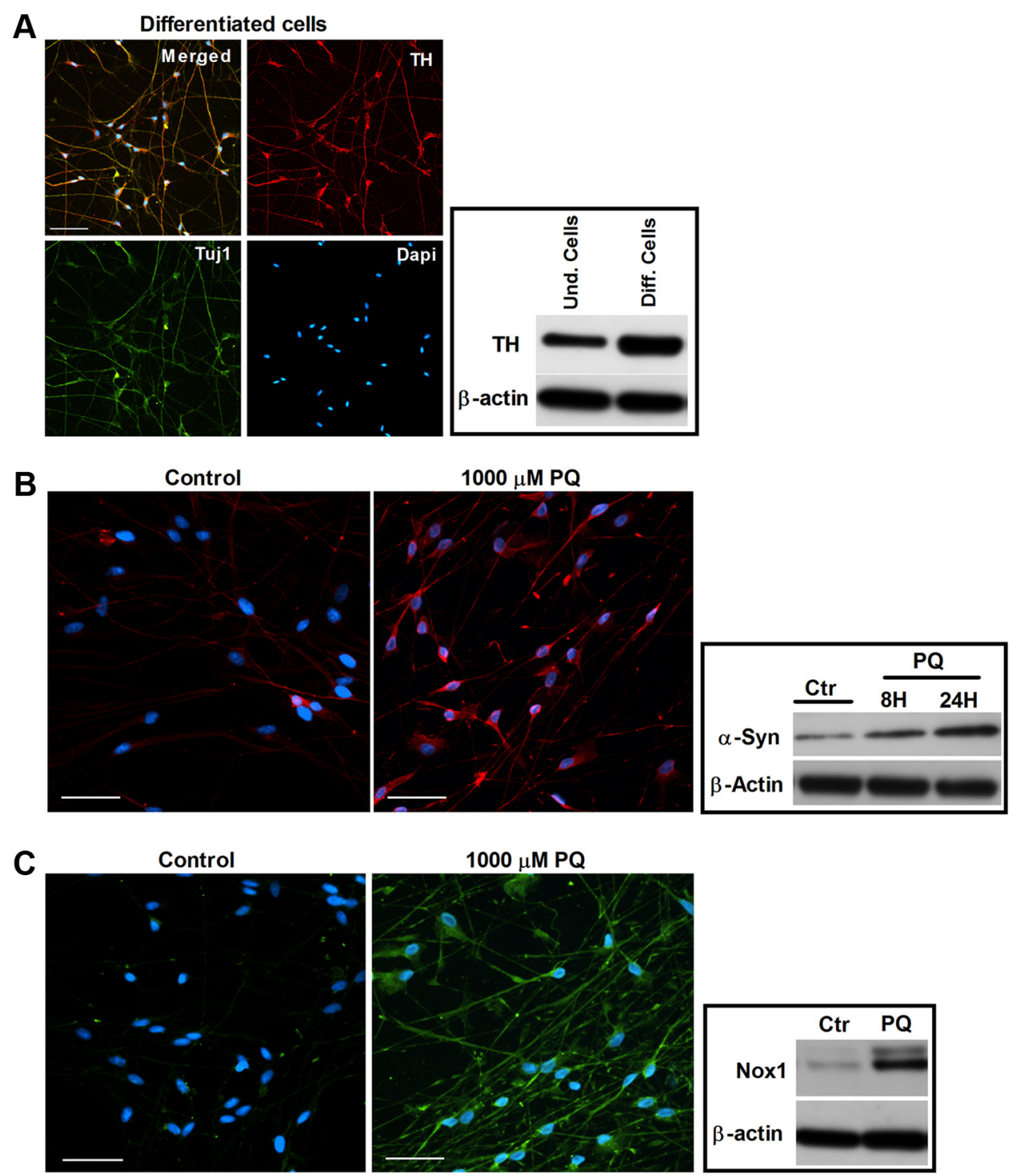

Figure 1. Increases in $\alpha$-synuclein and Nox1 in human dopaminergic neurons exposed to $\mathrm{PQ} . A$, Characterization of human ventral mesencephalic neuronal progenitor cell line, ReNcell VM, after differentiation (human dopaminergic neurons). Left, Depicts representative photomicrographs of TH, Tuj1, and DAPI immunostaining of ReNcell VM after 14 days differentiation. Right, Displays the expression of TH protein in ReNcell VM, before and after differentiation. $\boldsymbol{B}, \alpha$-Synuclein levels in differentiated human dopaminergic cells exposed to PQ. Left, Shows $\alpha$-synuclein immunoreactivity (red). Right, Represents $\alpha$-synuclein protein levels in immunoblot. C, Nox1 levels in differentiated human dopaminergic cells exposed $8 \mathrm{~h}$ to PQ. Left, Shows Nox1 immunoreactivity (green). Right, Illustrates Nox1 protein levels in immunoblot. $\beta$-Actin was used as an internal control. Und, undifferentiated; Diff, differentiated; Ctr, control; PQ, paraquat. Scale bars: $50 \mu \mathrm{m}$.

Myc, respectively. For transient overexpression of tagged $\alpha$-synuclein, $\mathrm{N} 27$ cells were plated onto 24 -well plates with coverslips at $0.5 \times 10^{5}$ cells per well $1 \mathrm{~d}$ before transfection. The next day, cells were transiently transfected with FLAG-WTsyn-myc. Briefly, $1 \mu \mathrm{g}$ of plasmid DNA was mixed with $6 \mu \mathrm{l}$ of Lipofectamine 2000 (Invitrogen) in $100 \mu \mathrm{l}$ of OptiMEM for 20 min before addition in the culture. After $6 \mathrm{~h}$ of incubation, the culture medium was changed and $100 \mu \mathrm{l}$ of Nox 1 shRNA/LVX viral particle was added to each well. Cells were maintained for an additional $36 \mathrm{~h}$ before treatment with $800 \mu \mathrm{M}$ or $1000 \mu \mathrm{M}$ PQ for 8 and $24 \mathrm{~h}$.

\section{Western blot}

For Western blot, brain tissues were lysed on ice in radioimmunoprecipitation assay buffer containing $50 \mathrm{~mm}$ Tris/ $\mathrm{HCl}, \mathrm{pH} 8.0,150 \mathrm{~mm} \mathrm{NaCl}, 2$ mu sodium orthovanadate, $1 \%$ Nonidet-P40 (NP-40), $0.5 \%$ sodium deoxycholate, and $0.1 \%$ SDS, containing $1 \%$ of a protease inhibitor mixture (AEBSF, pepstatinA, E-64, bestatin, leupeptin, and aprotinin). The soluble fraction was obtained and equal amounts of cell lysate protein were loaded in each lane of a $12 \%$ SDS-PAGE or $4 / 10 \%$ to $20 \%$ polyacrylamide gel. After electrophoresis and transfer onto a polyvinylidene difluoride (PVDF) membrane, specific protein bands were detected using ap- propriate primary antibodies (rabbit anti-Noxl, rabbit anti- $\alpha$ synuclein, mouse anti-Ubiquitin, mouse anti-tyrosine hydroxylase (TH), and mouse anti- $\beta$-actin) and secondary antibodies conjugated to alkaline phosphatase or hydrogen peroxidase (anti-rabbit or antimouse) followed by Enhanced Chemifluorescence (ECF) detection or Enhanced Chemiluminescence (ECL).

\section{Dot blot analysis}

For dot blot, brain tissues were homogenized in a buffer containing $0.32 \mathrm{M}$ sucrose, $1 \mathrm{~mm} \mathrm{NaHCO}, 1 \mathrm{~mm} \mathrm{MgCl}_{2}, 0.5 \mathrm{~mm} \mathrm{CaCl}_{2}$, and $1 \%$ of a protease inhibitor mixture (AEBSF, pepstatinA, E-64, bestatin, leupeptin, and aprotinin). The soluble fraction was obtained by centrifugation at $1000 \times g$ and $5 \mu \mathrm{l}$ of each sample, containing the same amount of protein, was spotted in a PVDF membrane. Membrane was air dried for $4 \mathrm{~h}$ and blocked overnight at $4^{\circ} \mathrm{C}$ in $5 \%$ nonfat dry milk TBST $(10 \mathrm{~mm}$ Tris- $\mathrm{HCl}, \mathrm{pH}$ 7.8, $100 \mathrm{~mm} \mathrm{NaCl}, 0.05 \%$ Tween 20) solution. Protein spots were detected using the primary antibody, rabbit anti-A1 loligomer $(0.5 \mu \mathrm{g} / \mathrm{ml})$ from Invitrogen, and secondary antibody conjugated to hydrogen peroxidase (anti-rabbit) followed by ECL detection. 
A
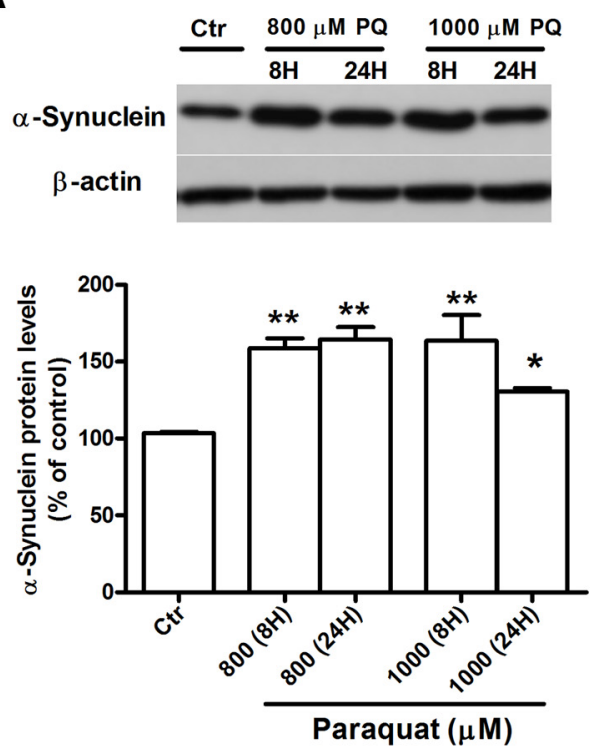

B
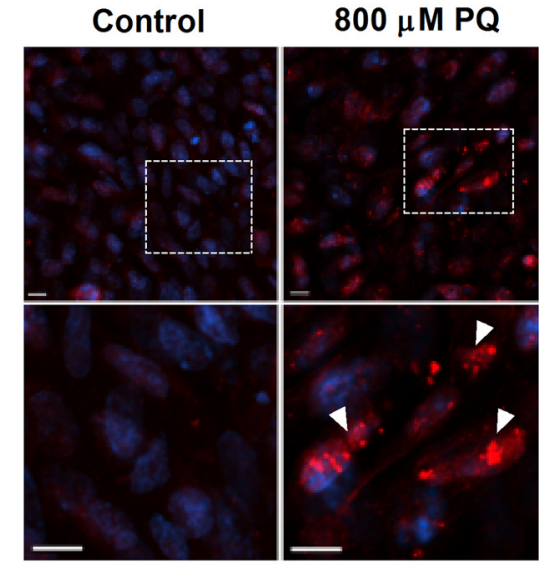

C
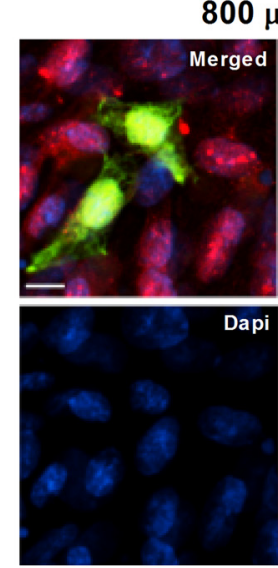

$800 \mu \mathrm{MPQ}$
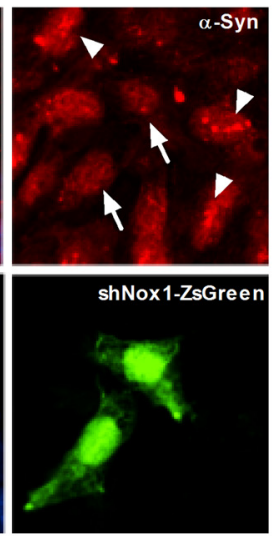

D

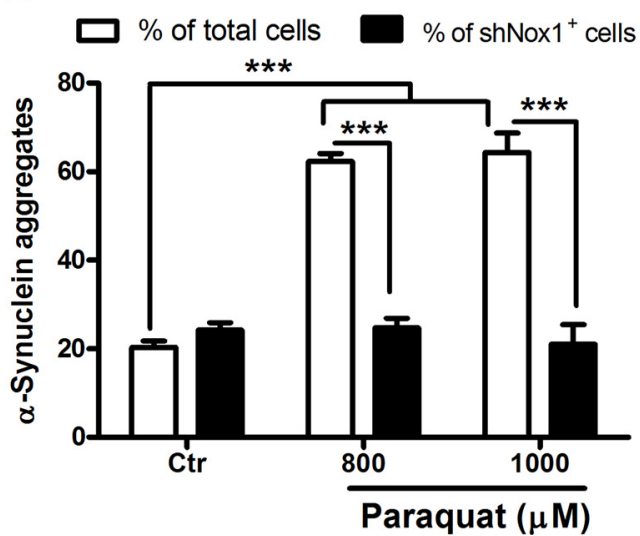

Figure 2. $\mathrm{PQ}$ induces increases of $\alpha$-synuclein expression and aggregation in N27 cells, an event prevented by Nox 1 knockdown. $A$, Representative immunoblot and quantitative analysis of $\alpha$-synuclein protein levels. $\alpha$-Synuclein protein was determined in total lysates of $\mathrm{N} 27$ cells exposed to PQ or control. $\beta$-Actin was used as an internal control. PQ significantly increased $\alpha$-synuclein protein levels, which were quantified using Quantity One software and normalized against $\beta$-actin. $\boldsymbol{B}$, Photomicrographs of aggregated $\alpha$-synuclein immunoreactivity (red) in control and PQ-treated cells. The bottom shows higher magnification of respective boxed areas in the top. $C, \alpha$-Synuclein fluorescence immunostaining of N27 cells incubated with Nox1 shRNA/LVX (shNox1-ZsGreen) viral particles for $36 \mathrm{~h}$ and then exposed to $800 \mu \mathrm{m}$ PQ. shNox1-ZsGreen-infected cells were identified by green fluorescence (ZsGreen) in cells. $\boldsymbol{D}$, Quantification of the cells depicting the bright, punctuated fluorescence, like the ones indicated with arrowheads in $\boldsymbol{B}$ and $\boldsymbol{C}$. More than 30 assigned fields were analyzed in each independent experiment and in average the minimum number of total cells counted per condition was 700 cells. Data are shown as the mean \pm SEM. Statistical analysis was performed using one-way ANOVA or two-way ANOVA, followed by Bonferroni's multiple-comparison test; ${ }^{*} p<0.05,{ }^{* *} p<0.01$, and ${ }^{* * *} p<0.001$. Arrowheads specify cells with aggregated $\alpha$-synuclein pattern, and the arrow indicates N27 cells showing double-staining for shNox1-ZsGreen and $\alpha$-synuclein. Ctr, control; PQ, paraquat. Scale bars: $10 \mu \mathrm{m}$.

\section{Measurement of oxidized proteins}

The levels of protein carbonyl were measured in protein extracts from the SN tissues, using the OxiSelect Protein Carbonyl Immunoblot Kit (Cell Biolabs), according to the manufacturer's instructions, with small modifications. Briefly, 5\% nonfat dry milk/PBST was used as blocking solution and antibody buffer, and the membrane was blocked for $1 \mathrm{~h}$ and incubated with the primary antibody overnight. Detection was performed using ECL.

\section{Immunocytochemistry}

After each respective treatment, cells were fixed in $4 \%$ paraformaldehyde (PFA) for $20 \mathrm{~min}$ and permeabilized with $0.1 \%$ Triton X-100 in PBS for $10 \mathrm{~min}$. Blocking was performed by incubation with $20 \%$ goat or donkey serum in PBS containing $0.1 \%$ Tween 20 for $90 \mathrm{~min}$ at room temperature. The cells were then incubated for $120 \mathrm{~min}$ at room temperature with the following primary antibodies, according to the aim of the experiment: goat anti-Nox1 (1:50), rabbit anti-TH $(1: 10,000)$, mouse anti-Flag (1:150), mouse anti- $\alpha$-synuclein (1:150), and rabbit anti-A11 $(2.5 \mu \mathrm{g} /$ $\mathrm{ml})$. After washing, cells were incubated for $120 \mathrm{~min}$ with the appropriate secondary antibodies conjugated to Alexa Fluor 647 or Alexa Fluor 488 (1:1000). For nuclear visualization coverslips were incubated with $2 \mu \mathrm{M}$ Hoechst for $10 \mathrm{~min}$. For quantification of Flag ${ }^{+}$and $\alpha$-synuclein ${ }^{+}$cells, $>30$ different fields per coverslip were analyzed on a Nikon inverted fluorescent microscope under a $20 \times$ and $40 \times$ magnification.

\section{Immunohistochemistry}

Following perfusion with saline and 4\% PFA in PBS, brains were removed, and forebrain and midbrain blocks were immersion fixed in $4 \%$ PFA and cryoprotected in sucrose. Serial coronal sections $(40 \mu \mathrm{m})$ were cut on a cryostat, collected in cryopreservative solution, and stored at $-20^{\circ} \mathrm{C}$. For immunolabeling studies, sections were incubated at room temperature with blocking solution for $1 \mathrm{~h}$ (5\% FBS and $0.3 \%$ Triton $\mathrm{X}-100$ in PBS, $\mathrm{pH}$ 7.5) and then with primary antibodies overnight. Finally, sections were incubated with secondary antibodies in blocking solution at room temperature for $1 \mathrm{~h}$. The primary antibodies used were mouse anti-TH (1:10,000), rabbit anti-Noxl (1:500), goat anti-4-HNE 
A
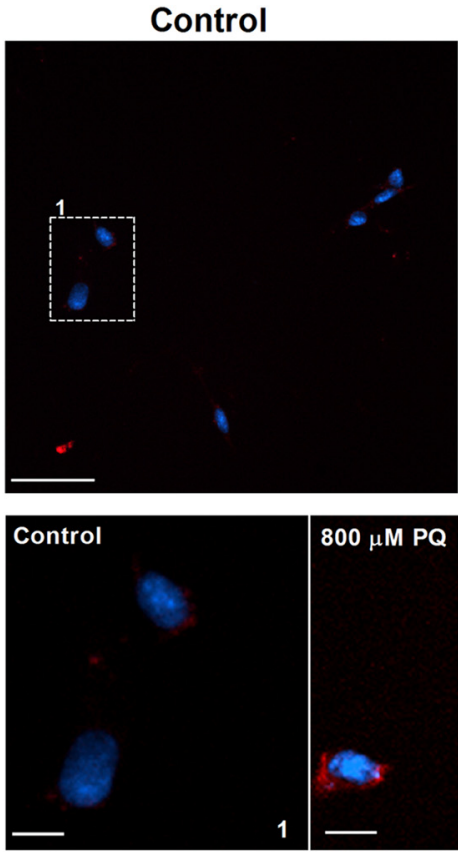

B
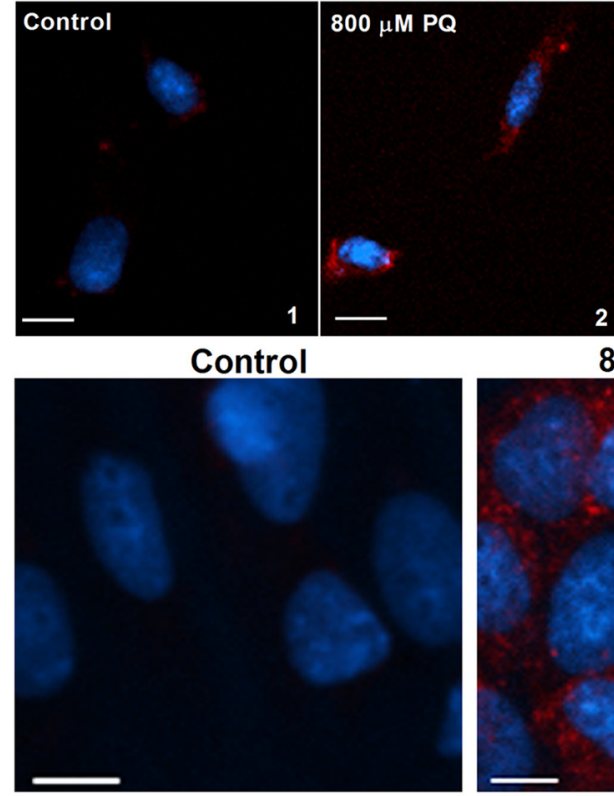

2

$800 \mu \mathrm{M} P Q$

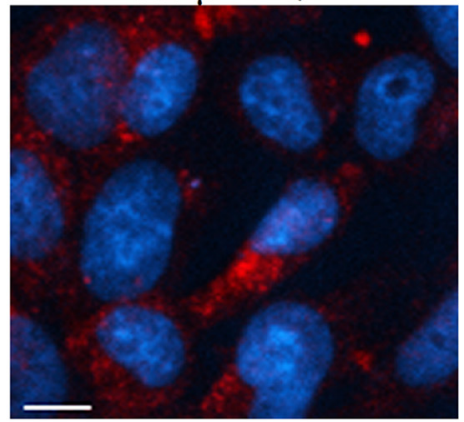

C

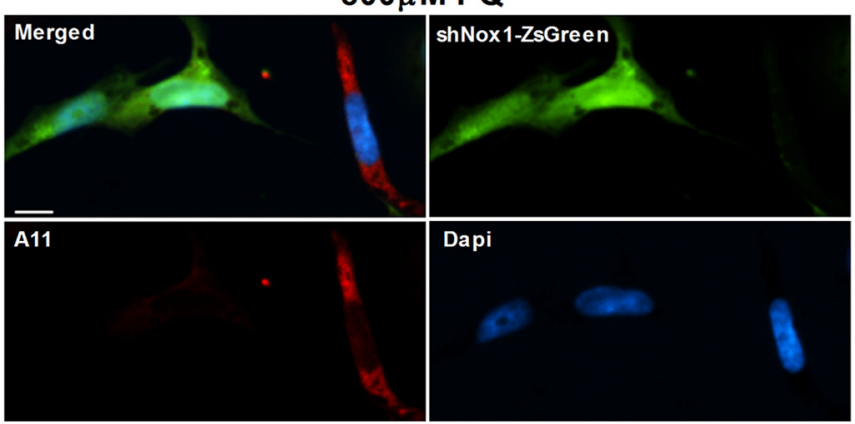

Figure 3. $\mathrm{PQ}$ increases levels of PK-resistant $\alpha$-synuclein and A11 oligomer formation in N27, which is reversed by Nox 1 knockdown. $\boldsymbol{A}$, PK-resistant $\alpha$-synuclein immunoreactivity in control and PQ-treated N27 cells. The bottom (scale bars: $10 \mu \mathrm{m}$ ) shows higher magnification of respective boxed areas shown in the top (scale bars: $50 \mu \mathrm{m}$ ). B, C, A11 immunoreactivity of control or PQ-treated N27 cells $(\boldsymbol{B})$ and in N27 cells incubated with Nox1 shRNA/LVX (shNox1-ZsGreen) viral particles for 36 h exposed to $800 \mu \mathrm{m} P Q(C)$. Scale bars: (for $\boldsymbol{B}, \boldsymbol{C}), 10 \mu \mathrm{m}$.

(1:700), mouse anti-ubiquitin (1:250), rabbit anti- $\alpha$-synuclein (1:150), and rabbit anti-A11 oligomers $(2.5 \mu \mathrm{g} / \mathrm{ml})$. The secondary antibodies were biotinylated anti-rabbit IgG, anti-goat IgG, or anti-rat IgG (1:200). The staining procedure was performed as indicated by the manufacturer of the Vectastain ABC kit and the reaction product visualized using 3,3' diaminobenzidine (DAB) reagent in TBS containing $0.02 \% \mathrm{H}_{2} \mathrm{O}_{2}$. The numbers of TH-immunoreactive cells in the SN were counted using an optical fractionator. Analysis was performed using a system consisting of a Nikon Eclipse E600 microscope (Morrell Instruments) equipped with a computer-controlled LEP BioPoint motorized stage (Ludl Electronic
Products), a DEI-750 video camera (Meyer Instruments), a Dell Dimension 4300 computer (Dell), and the Stereo Investigator (v. 4.35) software program (Microbrightfield).

Proteinase K digestion of cells and tissues for $\alpha$-synuclein aggregates detection

Immunocytochemistry for proteinase K (PK)resistant $\alpha$-synuclein was performed based on a methodology reported previously (Neumann et al., 2002), with some modifications. Briefly, fixed cells were permeabilized with $0.1 \%$ Tween 20 and then digested for $30 \mathrm{~min}$ at $37^{\circ} \mathrm{C}$ with PK $(10 \mu \mathrm{g} / \mathrm{ml})$. PK was inactivated with $3 \mathrm{~m}$ guanidine thiocyanate in $10 \mathrm{~mm}$ Tris- $\mathrm{HCl}$ solution for $10 \mathrm{~min}$. Between each step, cells were washed gently three times with PBS. Cells were then incubated for 60 min with blocking solution containing 10\% donkey serum followed by an overnight incubation with mouse anti- $\alpha$-synuclein antibody (1:150). The day after, cells were incubated with secondary antibodies conjugated to Alexa Fluor 647 donkey anti-mouse for $60 \mathrm{~min}$ and with $2 \mu \mathrm{M}$ Hoechst solution for $10 \mathrm{~min}$. For PK-resistant $\alpha$-synuclein evaluation in rat $\mathrm{SN}, 40 \mu \mathrm{m}$ sections from $4 \%$ PFA fixed tissues were washed twice in distillated water with $0.1 \%$ Tween 20 , and then incubated for $30 \mathrm{~min}$ in TBST. The tissues were incubated for $90 \mathrm{~min}$ at $55^{\circ} \mathrm{C}$ with $50 \mu \mathrm{g} / \mathrm{ml}$ PK in TBST and further washed three times in TBS. PK was denatured by incubating the tissues in a $3 \mathrm{~m}$ guanidine thiocyanate in 10 $\mathrm{mm}$ Tris- $\mathrm{HCl}$ solution for $10 \mathrm{~min}$. Sections were incubated with blocking solution for $1 \mathrm{~h}$ (TBST with $0.2 \%$ casein) and then with rabbit anti- $\alpha$-synuclein $(1: 150)$ at $4^{\circ} \mathrm{C}$ overnight. Finally, sections were incubated with biotinylated anti-rabbit IgG (1:200 blocking solution) at room temperature for $1 \mathrm{~h}$. The staining procedure was performed as indicated by the manufacturer of the Vectastain $\mathrm{ABC}$ kit and the reaction product visualized using $\mathrm{DAB}$ reagent in TBS containing $0.02 \% \mathrm{H}_{2} \mathrm{O}_{2}$.

\section{Data analysis and statistics}

Statistical analysis was performed with GraphPad Prism v.5 (GraphPad Software). Data are expressed as percentages of values obtained in control conditions, and are presented as mean \pm SEM of at least four animals (in vivo studies). Statistical analyses were performed using the one-way ANOVA or two-way ANOVA followed by Bonferroni's multiplecomparison test, or using Student's $t$ test. Values of $p<0.05$ were considered significant.

\section{Reagents}

FBS and gentamycin were purchased from Invitrogen BRL. Phenylmethylsulfonyl fluoride, NP-40, SP600125, Brij35, and bupropion were purchased from Sigma Chemicals. Mouse anti-TH was obtained from Transduction Laboratories; rabbit anti-Nox1, rabbit anti- $\alpha$ synuclein, and mouse anti-ubiquitin were obtained from Santa Cruz Biotechnology; and mouse anti- $\alpha$-synuclein from BD Transduction Laboratories. Goat anti-4-HNE and EGF were purchased from Millipore Bioscience Research Reagents. Rabbit anti-A11, Alexa Fluor 488 or Alexa Fluor 647, Hoechst 33342, Lipofectamine, ViraPower Lentiviral Expression System, 10-20\% SDS polyacrylamide gel and 10-20\% tricine gel, laminin, glutamax, DMEM/F12, and B27 supplement were purchased 

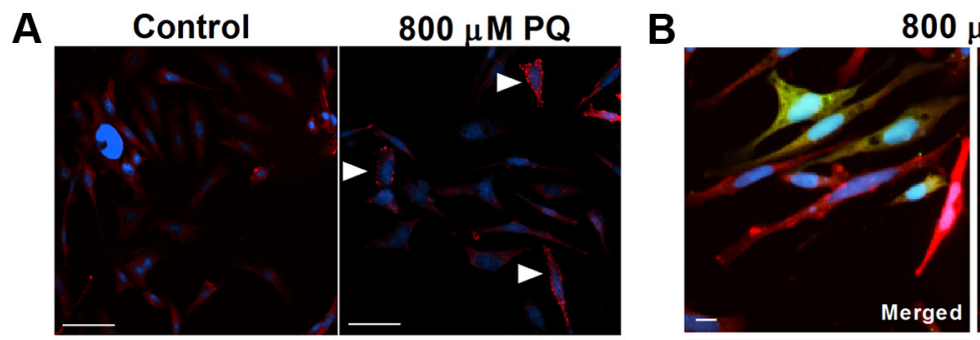

$800 \mu \mathrm{M} P Q$
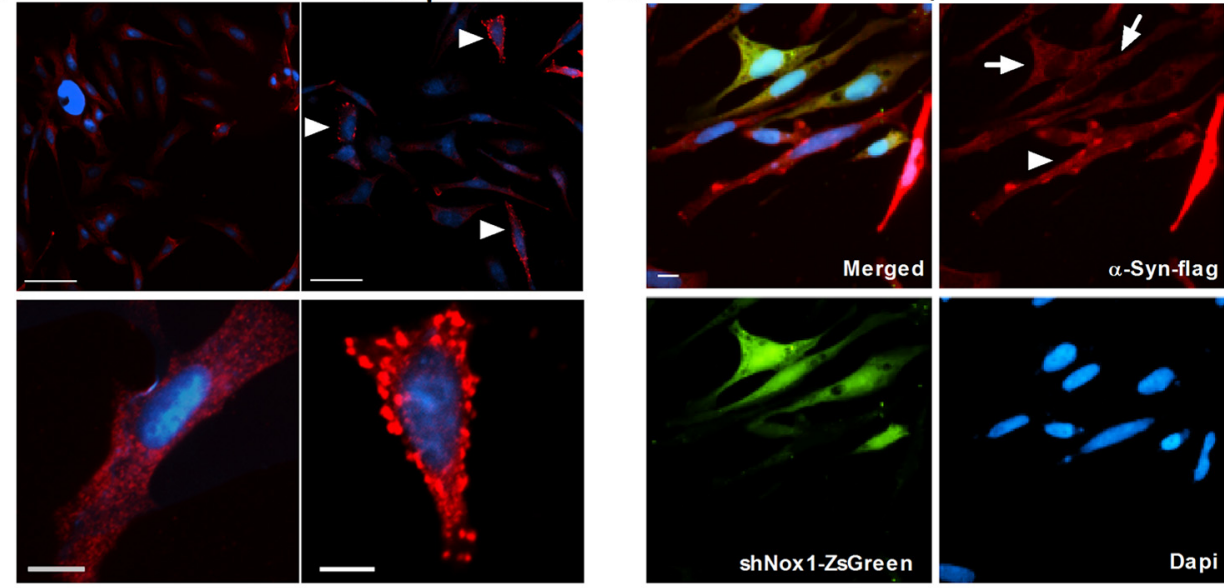

C

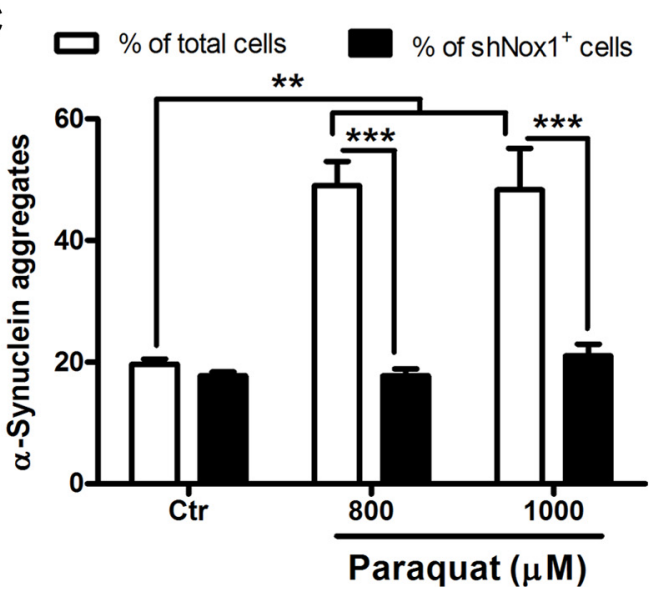

Figure 4. Nox1 knockdown inhibits aggregation of overexpressed WT $\alpha$-synuclein in N27 cells induced by PQ. $A$, Representative pictures of flag-tagged WT $\alpha$-synuclein immunoreactivity (red) in control and PQ-treated cells. Scale bars: (for top), $50 \mu \mathrm{m}$; (for bottom), $10 \mu \mathrm{m}$. B, Flag-tagged WT $\alpha$-synuclein fluorescence immunostaining of N27 cells incubated with Nox1 shRNA/LVX (shNox1-ZsGreen) viral particles and exposed to $800 \mu \mathrm{m}$ PQ. shNox1-ZsGreen-infected cells were identified by green fluorescence (ZsGreen) in cells. Scale bar, $10 \mu \mathrm{m}$. C, Quantification of the bright, punctuated fluorescent cells, indicated with arrowheads in $\boldsymbol{A}$ and $\boldsymbol{B}$. More than 20 assigned fields were analyzed in each independent experiment and in average the minimum number of total cells counted per condition was 400 cells. Data are shown as the mean \pm SEM. Statistical analysis was performed using one-way ANOVA or two-way ANOVA, followed by Bonferroni's multiplecomparison test; ${ }^{* *} p<0.01$ and ${ }^{* * *} p<0.001$. Arrowheads specify cells with aggregated $\alpha$-synuclein pattern, and arrows indicate N27 cells depicting double-staining for shNox1-ZsGreen and $\alpha$-synuclein-flag. Ctr, control; $\mathrm{PQ}$, paraquat.

from Invitrogen. ECF Western Blotting kit was obtained from GE Healthcare Bioscience. Vectastain ABC kit, biotinylated anti-rabbit, anti-mouse IgG, or anti-goat IgG were from Vector Laboratories. Taq polymerase was from Roche Applied Science. PQ, protease inhibitor mixture (AEBSF, aprotinin, bestatin hydrochloride, E-64-[N-(trans-epoxysuccinyl)-L-leucine 4-guanidinobutylamide], leupeptin, pepstatin A), heparin, PK, and guanidine thiocyanate were from Sigma-Aldrich. bFGF was purchased from Peprotech. Millipore Biomax-100K NMWL filter device (UFV2BHK40) was purchased from Millipore. CMV-IRES-hrGFP/AAV system was purchased from Stratagene and the p3xFLAG- $m y c$-CMV-23 expression vector from Sigma. pLVX-shRNA2-zsGreen1, Lenti-X 293T cells, and Xfect transfection reagent were purchased from Clontech. OxiSelect Protein Carbonyl Immunoblot Kit was purchased from Cell Biolabs. All other chemicals of reagent grade were from Sigma Chemicals or Merck.

\section{Results}

$\alpha$-Synuclein and Nox1 increases in human dopaminergic neurons after $P Q$ treatment

To evaluate the effects of PQ treatment on $\alpha$-synuclein and Nox1 expression in human dopaminergic neurons, human ventral mesencephalic neuronal progenitor cell line, ReNcell VM, was used (Donato et al., 2007). We first differentiated ReNcell VM into human midbrain neurons. After differentiation for 14 days, the obtained cultures were immunopositive for Tuj-1, a neuronspecific class III $\beta$-tubulin. Moreover, the majority ( $80 \%)$ of differentiated cells were $\mathrm{TH}$ positive, a specific marker of dopaminergic neuron, with an increased level of TH protein compared with undifferentiated cells (Fig. 1A). The effects of PQ on expression of $\alpha$-synuclein and Noxl were evaluated on these differentiated human dopaminergic cells. We observed that differentiated dopaminergic neurons express $\alpha$-synuclein, which increases over time under PQ treatment (Fig. $1 B$ ). Similarly, low basal level of Nox1 was highly elevated by PQ treatment, as shown by immunocytochemistry and Western blot analyses (Fig. 1C).

Overall, the results indicate that $\alpha$-synuclein may be a key player in PQ-mediated dopaminergic neuronal toxicity. Moreover, the result also suggests that Nox1 may have an important role in the mechanism of human dopaminergic neurodegeneration as induced by PQ.

\section{Nox1 knockdown significantly reduces PQ-induced} $\alpha$-synuclein expression and aggregation in dopaminergic cells To further study the role of Nox1 in $\alpha$-synucleinopathy caused by PQ in dopaminergic cells, the rat dopaminergic neuronal cell 
A

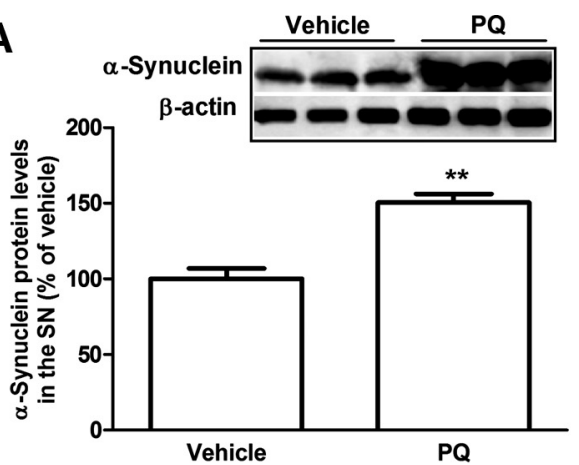

B
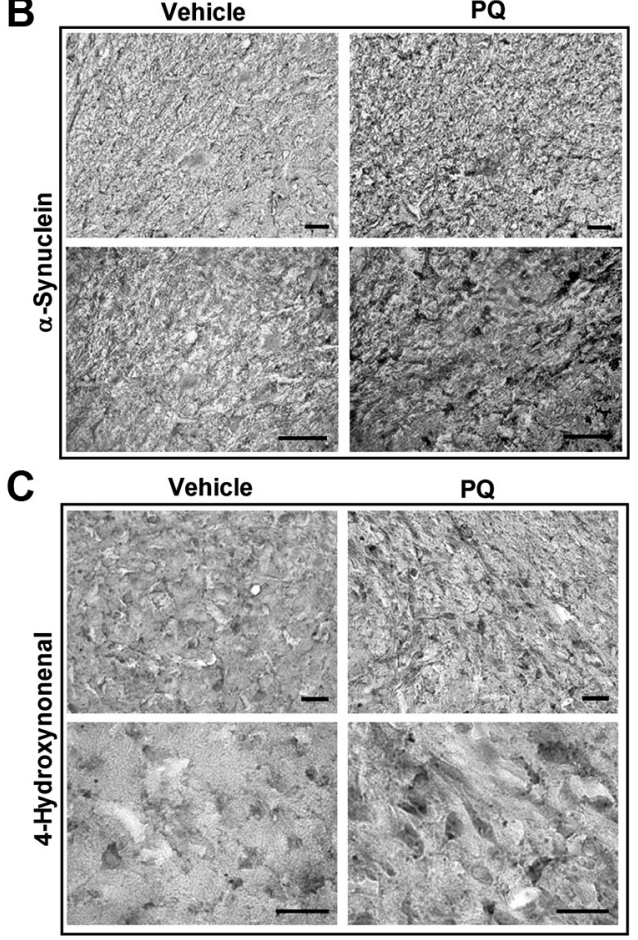

Figure 5. Increase in $\alpha$-synuclein and lipid peroxidation in the $\mathrm{SN}$ of rats administered with $\mathrm{PQ}$. A, Representative immunoblot and quantitative analysis of $\alpha$-synuclein protein levels. $\alpha$-Synuclein protein was determined in the total lysates of $\mathrm{SN}$ tissues of rats injected with vehicle or $\mathrm{PQ}$ by immunoblot analysis. $\beta$-Actin was used as an internal control. $\mathrm{PQ}$ significantly increased $\alpha$-synuclein protein levels, which were quantified using Quantity One software and normalized against $\beta$-actin. $\boldsymbol{B}, \boldsymbol{C}$, Representative photomicrographs of $\alpha$-synuclein $(\boldsymbol{B})$ and $4 \mathrm{HNE}(C)$ immunostaining in the $\mathrm{SN}$ of rats treated with vehicle or $\mathrm{PQ}$. Data are shown as the mean \pm SEM. Statistical analysis was performed using the Student's $t$ test; ${ }^{* *} p<0.01$. Scale bars: $50 \mu \mathrm{m}$.

line, N27 cells, was investigated. PQ significantly increased the levels of $\alpha$-synuclein expression. We observed 55 and $61 \%$ increases of $\alpha$-synuclein protein levels in N27 cells exposed to 800 $\mu \mathrm{M}$ PQ for 8 and $24 \mathrm{~h}$, respectively. When exposed to a $1000 \mu \mathrm{M}$ dose of PQ, an increase of 60 and $27 \%$, respectively, for 8 and $24 \mathrm{~h}$ incubation times was detected (Fig. 2A). Immunocytochemical evaluation showed that $\alpha$-synuclein aggregation was also induced by PQ. As shown in Figure $2 B$, we could see increased immunoreactivity for $\alpha$-synuclein in cultures treated with PQ, and, moreover, a pattern of aggregated $\alpha$-synuclein was observed in treated cultures, which was not detected in the untreated ones (Fig. $2 \mathrm{~B}$, arrowheads). The quantification of aggregated $\alpha$-synuclein-positive cells revealed an increase of $\alpha$-synuclein aggregation in cultures exposed to PQ compared with the control. As shown in Figure 2D (open bars), a statistical increase of 62 and 64\% in aggregation was
A
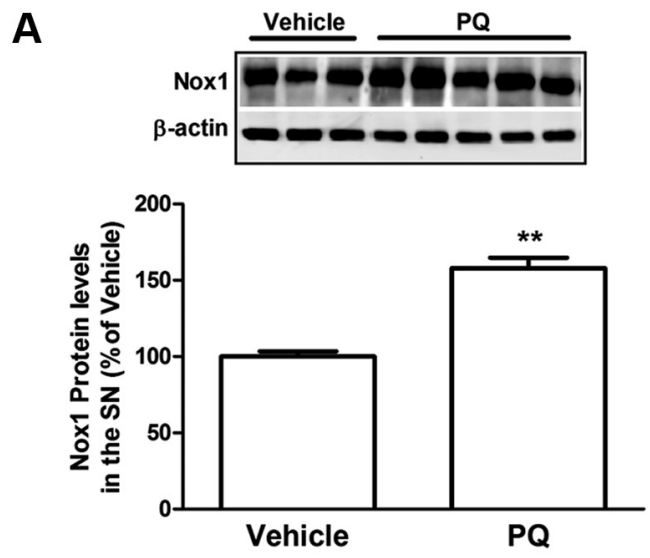

B

Vehicle $P Q$

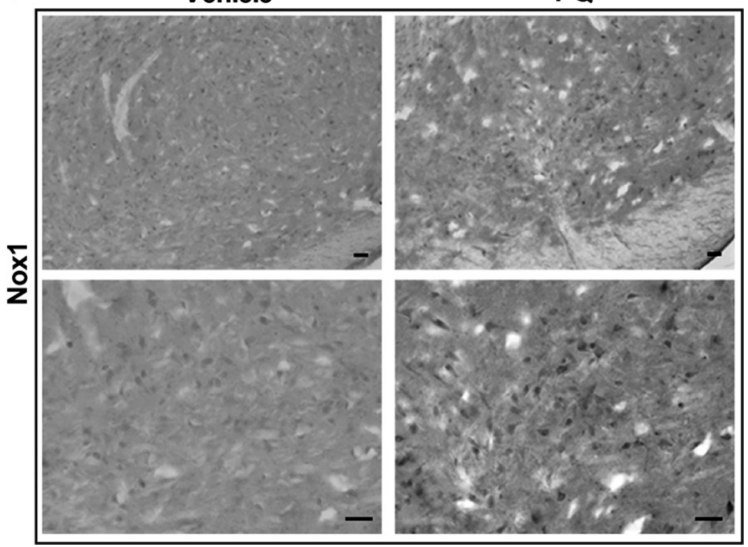

Figure 6. Increase in Nox1 protein levels in the $\mathrm{SN}$ of rats injected with $\mathrm{PQ}$. A, Representative immunoblot and quantitative analysis of Nox1 protein levels. Nox1 protein was determined in the total lysates of SN tissues of rats injected with vehicle or PQ by immunoblot analysis. $\beta$-Actin was used as an internal control. PQ significantly increased Nox1 protein, which was quantified using Quantity One software and normalized against $\beta$-actin. $\boldsymbol{B}$, Representative photomicrographs of Nox1-immunoreactivity in the $\mathrm{SN}$ sections of rats injected with vehicle or PQ. Nox1 immunoreactivity in the SN was increased in PQ-injected animals compared with vehicle. The result is expressed as percentage of vehicle. Data are shown as the mean \pm SEM. Statistical analysis was performed using the Student's $t$ test; ${ }^{* *} p<0.01$. Scale bars: $50 \mu \mathrm{m}$.

found in cultures exposed for $24 \mathrm{~h}$ to 800 and $1000 \mu \mathrm{M} P Q$, respectively. To confirm the effect of PQ in $\alpha$-synuclein aggregation, we have further evaluated the levels of $\alpha$-synuclein resistant to PK digestion, since it was previously reported that $\alpha$-synuclein aggregates are resistant to limited PK digestion (Neumann et al., 2002). As shown in Figure 3A, N27 cells exposed to PQ depict higher PKresistant $\alpha$-synuclein immunoreactivity, an indicator of higher $\alpha$-synuclein aggregation. We have further evaluated $\alpha$-synuclein aggregation by investigating the levels of A11 immunoreactivity in untreated and PQ-treated N27 cell, as the anti-A11 oligomer antibody was previously reported to efficiently detect $\alpha$-synuclein aggregation (Winner et al., 2011). Figure 3B shows high A11 immunoreactivity in cultures exposed to PQ when compared with the controls, clearly indicating increased $\alpha$-synuclein aggregation induced by PQ. As expected, this group of results infers that $\mathrm{PQ}$ induces increased levels of $\alpha$-synuclein expression as well as aggregation.

To explore the contribution of Noxl in the changes of $\alpha$-synuclein induced by PQ, we knocked down Noxl, using lentivirus-mediated Nox1 shRNA overexpression (shNox1ZsGreen), and exposed N27 cells to PQ. The results showed that PQ-induced $\alpha$-synuclein aggregation was lower in cells overexpressing Nox1 shRNA (Fig. 2C). After quantifying the number of cells depicting both shNox1-ZsGreen and $\alpha$-synuclein aggre- 
gates, no statistical differences were found between untreated and PQ-treated cultures as shown in Figure 2D (solid bars). The same result was found when analyzing A11 immunoreactivity in those cells. As shown in Figure 3C, shNox1-ZsGreenpositive cells clearly had lower immunoreactivity for A11 compared with shNox1ZsGreen-negative cells.

Next, we sought to understand if Nox1 has a role only in the expression pathway of $\alpha$-synuclein leading to protein increase and subsequent aggregation, or if it was also acting directly in its aggregation capability. Flag-tagged wild-type (WT) $\alpha$-synuclein and shNox1-ZsGreen were overexpressed in N27 cells, and then cells were exposed to PQ. Strong cytoplasmic aggregation was induced by PQ treatment as detected by anti-flag immunostaining (Fig. 4A). A significant 2.5-fold increase of aggregation was observed in cells exposed to PQ when compared with control cells (Fig. 4C, open bars). Furthermore, when aggregation was analyzed in shNox1-ZsGreen-positive cells exposed to $\mathrm{PQ}$, aggregation levels were not statistically different from control cells (Fig. $4 C$, solid bars). Aggregation was decreased by a 2.5 -fold in shNox1-ZsGreen-positive cells (Fig. $4 B$, arrow) when compared with shNox1-ZsGreen-negative cells (Fig. 4B, arrowhead) for both concentrations of PQ (Fig. $4 B, C$ ).

Altogether the above results are highly suggestive that Noxl is an important intermediary in regulation of both expression and the aggregation process of $\alpha$-synuclein in dopaminergic cells stressed with PQ.

\section{PQ intraperitoneal injection causes increases in $\alpha$-synuclein and Nox1} protein level as well as oxidative stress in the rat $\mathrm{SN}$

To validate the significance of our in vitro results, we moved forward to in vivo studies, using a PQ-inducing rat model of PD. Our first observations showed that PQ injection in rats induced an increase of $50 \%$ in $\alpha$-synuclein protein levels in the $\mathrm{SN}$ as determined by Western blot (Fig. 5A). $\alpha$-Synuclein immunoreactivity in the $\mathrm{SN}$ was also increased after PQ administration, as shown in Figure $5 B$. The involvement of Nox1 in PQ-mediated dopaminergic cell death in mice was reported in a previous study of our group (Cristóvão et al., 2009). In the present study, PQ insult also induced increased Nox1 protein level in the rat SN. As shown in Figure 6A, animals exposed to PQ showed 58\% higher levels of Noxl protein than the group treated with vehicle. The upregulation of Nox1 in the SN of rats injected with PQ was further confirmed by immunohistochemistry as shown in Figure $6 B$.

Nox enzymes are responsible for ROS production; we then evaluated if increases in Noxl were also accompanied by increased oxidative stress markers in rat tissues exposed to PQ. As depicted in Figure 5C, an increase in 4-HNE immunoreactivity, a well established maker for lipid peroxidation, was found in the SN of rats treated with PQ compared with rats treated with vehicle. The above results are in accordance with the ones observed in vitro, and emphasize that under PQ insult, $\alpha$-synuclein, Nox1, and oxidative stress may act as partners to enhance dopaminergic neurodegeneration.

The establishment of the rat model used in the present work was based on our previous reported results showing in mice the loss of dopaminergic neurons in the SN after PQ exposure (Cristóvão et al., 2009).

\section{The specific knockdown of Nox1 reduced rat dopaminergic neuronal loss induced by $P Q$}

To investigate the role of Nox1 in oxidative stress, dopaminergic neuronal death, and $\alpha$-synuclein expression and aggregation changes induced by PQ in rats we achieved Nox1 knockdown in the SN by using AAV-mediated Noxl shRNA overexpression. Nox1 knockdown was achieved by stereotaxic delivery of AAV2 particles into the rat SN. PQ intraperitoneal injections were performed 4 weeks after the AAV2 injection, as depicted in Figure $7 A$. AAV2 containing GFP vector was used as a negative control. To verify Nox1 knockdown efficiency, Nox1 levels in the SN of each group of animals were investigated by Western blot and immunohistochemistry analysis. Nox1 knockdown in the SN significantly reduced PQ-mediated Nox1 increases (Fig. $7 B, C$ ). As 

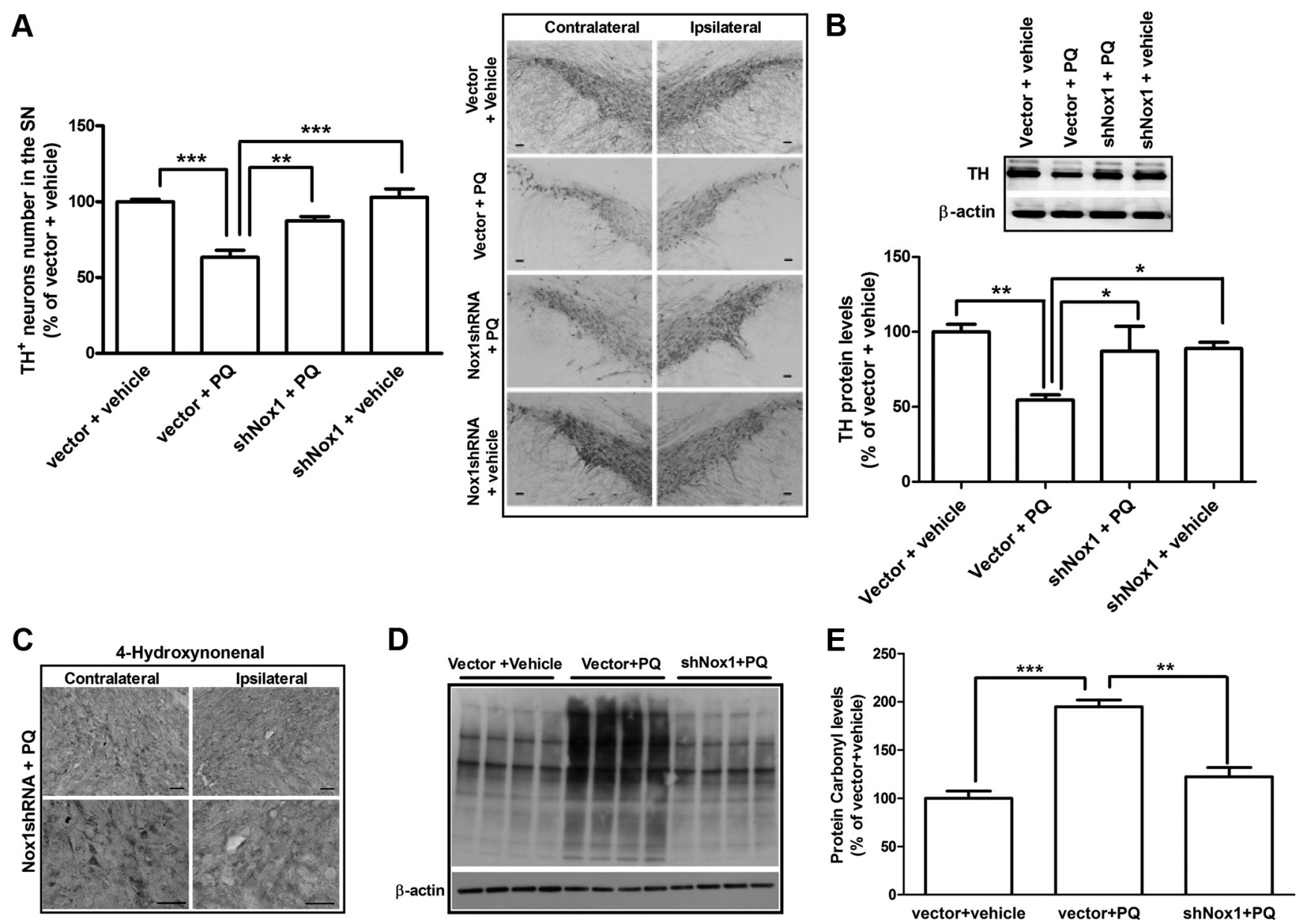

Figure 8. Nox 1 knockdown reduced $S N$ dopaminergic neuronal death induced in rats administered with $P Q . A$, Representative photomicrographs of TH immunostaining and quantitative analysis of TH-positive dopaminergic neurons in the SN of rats after Nox1 knockdown. Representative photomicrographs of TH immunoreactivity in the SN of the contralateral and ipsilateral sides of brain sections of the four experimental groups. TH-positive neurons in the ipsilateral side were stereologically counted. $\boldsymbol{B}$, Representative immunoblot and quantitative analysis of TH protein levels. TH protein was determined in total lysates of the rat's $S \mathrm{~N}$ tissues in the ipsilateral side by immunoblot analysis. $\beta$-Actin was used as an internal control. TH protein levels were quantified using Quantity One software and normalized against $\beta$-actin. C, Representative photomicrographs of 4-HNE immunostaining in the SN of the contralateral and ipsilateral sides of brain sections of rats from shNox1 $+\mathrm{PQ}$ group. Scale bars, $50 \mu \mathrm{m} . \boldsymbol{D}, \boldsymbol{E}$, Immunoblot $(\boldsymbol{D})$ and quantitative analysis $(\boldsymbol{E})$ of protein carbonyl levels determined in total lysates of rats' ipsilateral SN tissues. $\beta$-Actin was used as an internal control. The results are expressed as percentage of vector + vehicle. Data are shown as the mean \pm SEM. Statistical analysis was performed using one-way ANOVA followed by Bonferroni's multiple-comparison test; ${ }^{*} p<0.05,{ }^{* *} p<0.01$, and ${ }^{* * *} p<0.001$.

shown in Figure $7 B$, animals treated with vector + PQ showed statistically higher levels of Nox1 protein $(70 \%)$ compared with animals treated with vector + vehicle. Compared with animals treated with vector $+\mathrm{PQ}$, animals treated with shNox $1+\mathrm{PQ}$ showed a $40 \%$ decrease in Nox1 protein levels in the SN (Fig. 7B). Nox1 levels in the $\mathrm{SN}$ of each group of animals were also investigated by immunohistochemistry, confirming the decrease in Nox1 immunoreactivity in the SN of animals exposed to Nox1shRNA + PQ compared with the ones exposed to vector $+\mathrm{PQ}$ (Fig. 7C). These results confirmed that AAV-mediated Nox1 knockdown in vivo significantly reduced PQmediated increase in Nox1 level, validating our knockdown method.

To investigate the contribution of Noxl to the dopaminergic neurotoxicity induced by PQ in each group of animals, the levels of $\mathrm{TH}$ protein in the $\mathrm{SN}$ were investigated by Western blot and the numbers of $\mathrm{TH}$-positive dopaminergic neurons in the substantia nigra pars compacta were obtained by stereological analysis. Administration of vector $+\mathrm{PQ}$ significantly reduced $\mathrm{TH}$ protein levels to $65 \%$ compared with the control group injected with vector + vehicle, while $\mathrm{TH}$ protein levels were recovered to $87 \%$ in the group in which Nox1 was knocked down before PQ exposure (Fig. $8 \mathrm{~B}$ ). The stereological count of TH-positive neu- rons showed that Nox1 knockdown significantly reduced PQelicited dopaminergic neuronal loss from $37 \%$ in the group treated with vector + PQ to $13 \%$ in the Nox1shRNA + PQ group (Fig. 8A). In addition, we found that Nox1 knockdown also reduced oxidative stress levels, as shown by the levels of lipid peroxidation and protein oxidation. Increased immunoreactivity of 4-HNE (Fig. 8C) and protein carbonyl (Fig. 8D,E) in animals treated with PQ was decreased in the Nox1shRNA + PQ group. Protein carbonyl levels were significantly increased by $95 \%$ after PQ exposure when compared with vector + PQ group, and reduced to $22 \%$ when Nox1 was knocked down (Fig. $8 E$ ). These results have shown that Nox1 knockdown reduced dopaminergic neuronal death and oxidative stress induced by PQ, which was in accordance with our two previous report observations showing that the Nox system plays an important role in PQ- and 6-OHDA-mediated dopaminergic neurotoxicity.

Increased expression and aggregation of $\alpha$-synuclein induced by $P Q$ relies on Nox1 protein in the rat $S N$

Herein, we sought to evaluate the involvement of Nox1 in the effect of PQ on $\alpha$-synuclein expression levels and aggregation in 
A
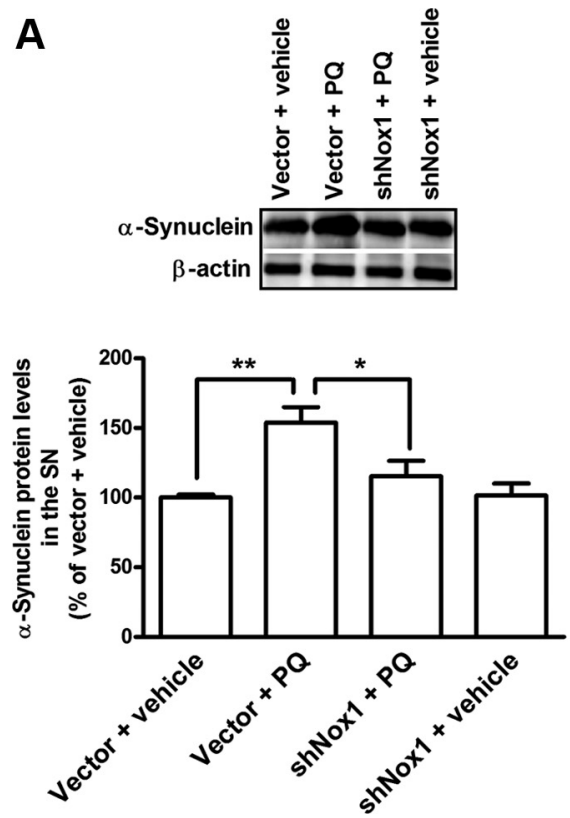

B

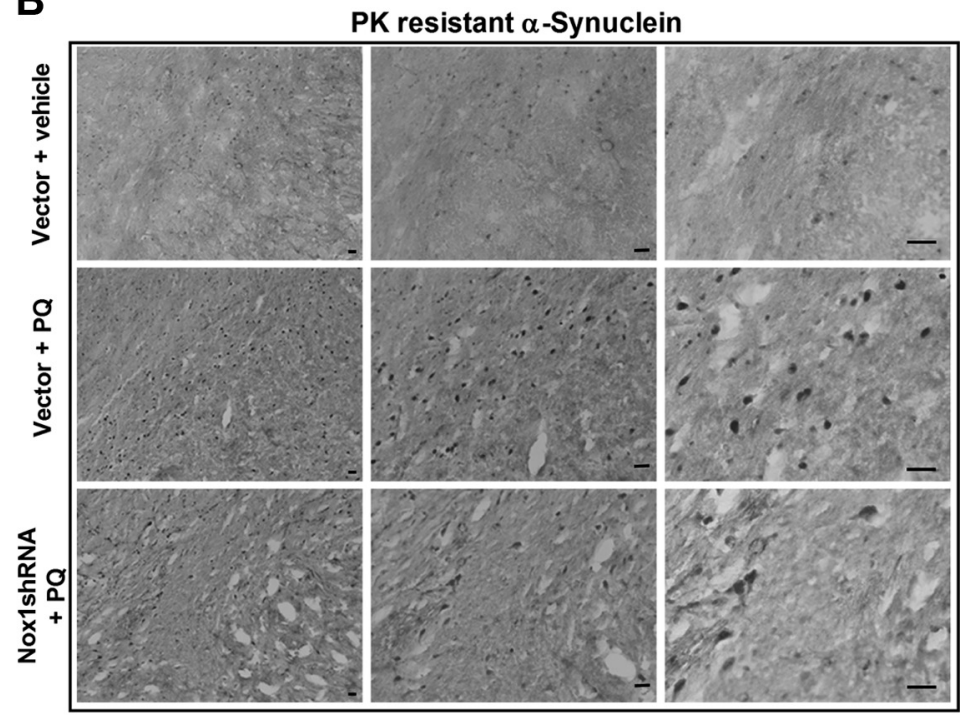

Figure 9. Nox1 knockdown reduced PQ-mediated $\alpha$-synuclein increase in the SN dopaminergic neurons. $\boldsymbol{A}$, Representative immunoblot and quantitative analysis of $\alpha$-synuclein protein levels. $\alpha$-Synuclein protein was determined in total lysates of the rats SN tissues in the ipsilateral side by immunoblot analysis. $\beta$-Actin was used as an internal control. $\alpha$-Synuclein protein levels were quantified using Quantity One software and normalized against $\beta$-actin. The results are expressed as percentage of vector + vehicle. Data are shown as the mean \pm SEM. Statistical analysis was performed using one-way ANOVA followed by Bonferroni's multiple-comparison test; ${ }^{*} p<0.05$ and ${ }^{* *} p<0.01$. B, Representative photomicrographs of PK-resistant $\alpha$-synuclein immunoreactivity in the ipsilateral SN of brain sections of the four experimental groups. Increased PK-resistant $\alpha$-synuclein immunostaining observed in the vector + PQ group was significantly decreased by Nox1 knockdown as observed in shNox1 $+\mathrm{PQ}$ group. Scale bars, $50 \mu \mathrm{m}$.

vivo. We investigated $\alpha$-synuclein, protein aggregation, and ubiquitin levels in the $\mathrm{SN}$ of each group of animals by Western blot, dot blot, and immunohistochemical analyses. We found significant increases of 54, 68, and 43\%, in $\alpha$-synuclein, A11positive oligomers and ubiquitin protein levels, respectively, in the vector + PQ-treated group when compared with the vector + vehicle group (Figs. 9A, 10A,C). Moreover, Nox1 knockdown reduced by 37,50 , and $43 \%$ the PQ-mediated $\alpha$-synuclein, A11 oligomers, and ubiquitin levels, respectively, compared with the vector + PQ (Figs. 9A, 10A,C). To further evaluate in vivo the effect of Nox1 knockdown on PQ-induced $\alpha$-synuclein aggregation we have also investigated the levels of $\alpha$-synuclein resistant to $\mathrm{PK}$ digestion. We were able to observe an increase in PKresistant $\alpha$-synuclein immunoreactivity in the rat $\mathrm{SN}$ exposed to vector $+\mathrm{PQ}$, but not in the vector + vehicle group. A significant reduction in PK-resistant $\alpha$-synuclein staining was observed in the group in which Noxl was knocked down before PQ injection (Nox1shRNA + PQ) (Fig. 9B). Immunohistochemistry evaluations revealed a significant increase in the immunoreactivity of A11 oligomers in the SN of rats exposed to PQ, which was decreased in the group exposed to PQ in which Nox1 was knocked down (Fig. 10B). The involvement of Nox1 in PQ-induced changes in ubiquitin in the $\mathrm{SN}$ was also evaluated and the significant increase in ubiquitin immunoreactivity observed in the rat SN exposed to vector + PQ was reversed by Nox1 knockdown $($ Nox1shRNA + PQ) (Fig. 10D). Together our results are highly suggestive of an active role of Nox1 in $\alpha$-synucleinopathy induced by PQ at transcriptional levels as well as post-translational aggregation mechanism.

\section{Discussion}

In the present work, we perceive Nox1 as a crucial intermediary, between an environmental factor responsible for oxidative stress condition and $\alpha$-synuclein transcriptional regulation and aggre- gation. We provide evidence that suggests, under oxidative stress, as induced by PQ, $\alpha$-synuclein expression and aggregation levels are increased, which can be ameliorated to normal by Nox1 knockdown. And most important, dopaminergic loss in the SN of rats exposed to PQ can also be recovered by Nox1 knockdown, suggesting that Nox1-derived ROS play a crucial role in $\alpha$-synuclein pathology as along with dopaminergic neuronal degeneration.

$\alpha$-Synuclein is a distinctive genetic factor in PD pathogenesis, in which its alterations and mutations were linked to the development of the disease (Beyer et al., 2009; Cookson, 2009). Oxidative stress has also been largely mentioned as a strong contributor to the development of the disease, and it has also been involved in PQ-induced dopaminergic neurodegeneration (Dexter et al., 1994; Alam et al., 1997; Zhang et al., 1999). Physiologically, ROS are generated as a byproduct of several biological reactions from organelles like mitochondria, and Nox is the specialized system that produces ROS, but not as a byproduct (Sorce and Krause, 2009), and our recent studies demonstrated that Nox1 serves as a major contributing factor in dopaminergic neuronal degeneration in both 6-OHDA and PQ-mediated PD rodent models (Cristóvão et al., 2009; Choi et al., 2012). Our results using ReNcell VM cultures, which have been previously validated as an in vitro model of human dopaminergic neurons (Donato et al., 2007; Wood-Kaczmar et al., 2008), showed an increase in Nox1 level following PQ exposure (Fig. 1C). Nox1 and the oxidative stress marker were also found increased in rats exposed to PQ (Figs. 5, 6). The involvement of Nox1 in the mechanism of PQ-induced neurotoxicity was first demonstrated by our study, suggesting that Nox1 is involved in oxidative stress and consequent dopaminergic neuronal death (Cristóvão et al., 2009). More recently, we reported that Nox1-induced ROS also contributes to dopaminergic neurodegeneration induced by 6-OHDA 
A
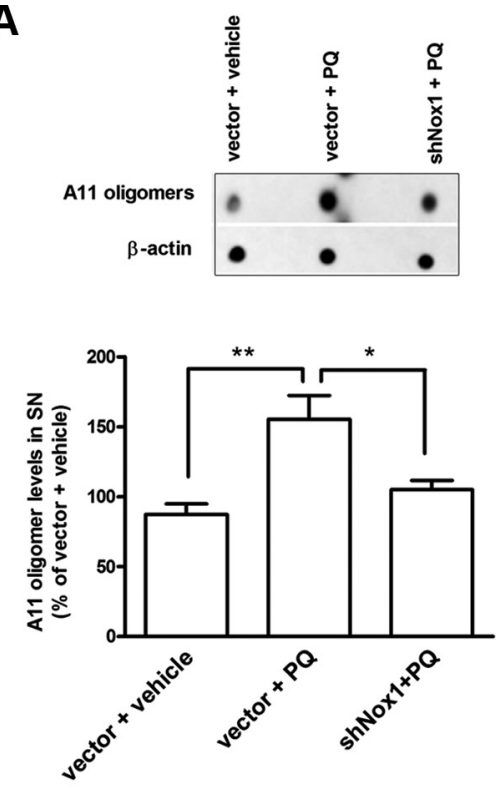

C
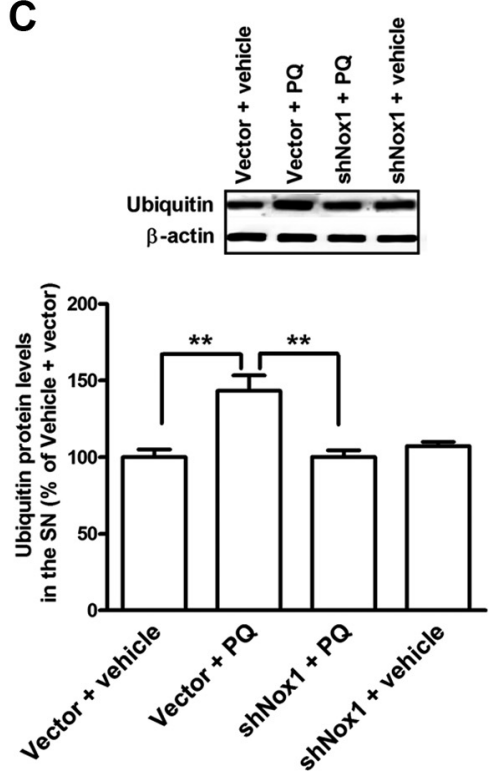

D

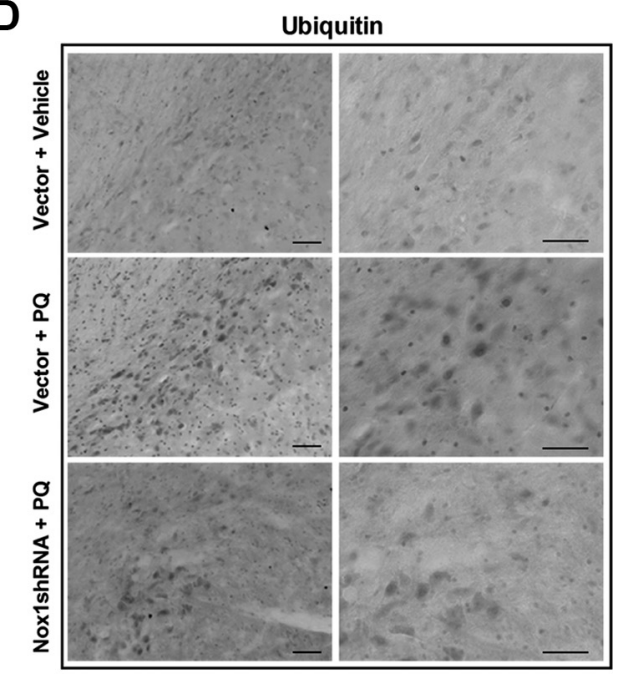

Figure 10. Nox1 knockdown reduced PQ-mediated A11 oligomers and ubiquitin increase in the SN dopaminergic neurons. Representative immunoblot and quantitative analysis of $A 11$ oligomers $(\boldsymbol{A})$ and ubiquitin $(\boldsymbol{C})$ levels determined in total lysates of the rats $S N$ tissues in the ipsilateral side by immunoblot analysis. $\beta$-Actin was used as an internal control. A11 oligomer levels were quantified using Quantity One software and normalized against $\beta$-actin. The results are expressed as percentage of vector + vehicle. Data are shown as the mean \pm SEM. Statistical analysis was performed using one-way ANOVA followed by Bonferroni's multiple-comparison test; ${ }^{*} p<0.05,{ }^{* *} p<0.01$ Representative photomicrographs of A11 oligomers $(\boldsymbol{B})$ and ubiquitin (D) immunoreactivity in the ipsilateral SN of brain sections of the three experimental groups. $\boldsymbol{B}$, Bottom right shows higher magnification of the respective boxed area shown in the right top. Scale bars, $50 \mu \mathrm{m}$.

(Choi et al., 2012), a well known toxin used to mimic PD pathogenesis in vitro and in vivo (Javoy et al., 1976; Terzioglu and Galter, 2008). We showed that the nuclear localization of Nox1 is responsible for nuclear DNA damage and degeneration of dopaminergic neurons after 6-OHDA treatment. Altogether this evidence emphasizes the importance of Noxl as a crucial participant in dopaminergic neurodegeneration.

$\alpha$-Synuclein point mutations, A30P, A53T, and E46K, were found in the familial forms of early onset PD and they are responsible for the changes in $\alpha$-synuclein aggregation properties (Hardy et al., 2009). Interestingly, elevated expression of WT $\alpha$-synuclein due to the multiplications of SNCA has also been identified in early onset familiar PD (Singleton et al., 2003; Chartier-Harlin et al., 2004), leading to the view that WT protein could cause PD in a dose-dependent manner. Although this fact fortifies the importance of the transcriptional regulation of $\alpha$-synuclein, relatively few studies have focused on the role of oxidative stress in the expression level and transcriptional control of $\alpha$-synuclein. This is at least partly due to the lack of proper in vitro and in vivo model systems that successfully demonstrate the increased endogenous $\alpha$-synuclein level. Importantly, in the current work, both in vitro and in vivo models showed significant changes in $\alpha$-synuclein expression under PQ exposure. The levels of $\alpha$-synuclein in ReNcells and N27 cells cultures exposed to PQ were prominently increased with time (Figs. $1 B, 2 A$ ), and significant increase in $\alpha$-synuclein was also observed in the rat $\mathrm{SN}$ exposed to PQ as well (Fig. 5). Previous observations have shown that PQ increases $\alpha$-synuclein expression levels and aggregation (Uversky et al., 2001; Manning-Bog et al., 2002), and that could be directly related to PQ-derived ROS generation (Krishnan et al., 2003). However, the molecular mechanism behind this effect is still elusive. Altogether these findings are suggestive of a possible relationship between increased ROS and the transcriptional regulation of $\alpha$-synuclein, consistent with studies showing that toxic insults involving ROS production induce increased $\alpha$-synuclein levels in the SN (McCormack et al., 2005). In PC12 cells as well as in primary cortical neurons from rat, it was demonstrated that $\alpha$-synuclein expression in response to neurotrophins is regulated by the MAP/ERK and PI3-K pathways (Clough and Stefanis, 2007; Clough et al., 2011), which are also known to be activated under oxidative stress conditions (Miller et al., 2009). This suggests a possible relationship between increased ROS and transcriptional regulation of $\alpha$-synuclein through these pathways. The above idea reinforces our hypothesis that Noxl-ROS generation might be a key regulator controlling $\alpha$-synuclein expression. Nevertheless, the effects of ROS in transcriptional regulation are broad, including epigenetic alterations (Zawia et al., 2009), transcription factors binding regulation (Clough et al., 2009), or DNA damage (Turk et al., 1995). How Noxl-derived ROS regulates the transcription of $\alpha$-synuclein remains to be investigated.

In addition to the effect of PQ in $\alpha$-synuclein expression levels, we also found that PQ increased the aggregation of $\alpha$-synuclein (Figs. 2-4) in N27 cells as well as in the rat SN, accompanied with increased levels of ubiquitin (Figs. 9, 10C,D). These findings are in agreement with previous reports showing increased $\alpha$-synuclein aggregation in mice exposed to PQ (Manning-Bog et al., 2002). Based on this, we sought to enlarge 
our view of the disease paradigm and search for a potential relationship between Nox1 and $\alpha$-synuclein aggregation. Nox1 knockdown achieved by viral delivery of shRNA against Nox1 significantly reduced $\alpha$-synuclein aggregation in both in vitro and in vivo. A large number of reports have similarly shown that AAV-mediated shRNA delivery to the CNS for targeted knockdowns of specific genes can be achieved (Harper et al., 2005), including two of our recent works (Choi et al., 2011, 2012). On the other hand, the lentivirus system that delivers genes to cells showed higher infection efficiency then AAV2, but with less specificity, and was able to infect divided and nondivided cells. In that sense this system is more suitable for in vitro gene delivery using a cell culture system containing only one type of cells. Lentivirusmediated Nox1 knockdown in N27 cells led to significant reduction in PQ-induced $\alpha$-synuclein aggregation. Several methods were used for this evaluation and we found clear evidence that Nox1 is involved in the aggregation process of $\alpha$-synuclein induced by PQ (Figs. $2 C, D, 3 C, 4 B, C$ ). Importantly, Noxl knockdown also prevented aggregation of WT $\alpha$-synuclein overexpressed, suggesting that along with its involvement in the transcriptional regulation, Nox1-induced ROS may also play a role in stabilizing the protein, leading to aggregation of $\alpha$-synuclein.

AAV2-mediated Nox1 knockdown in the rat $\mathrm{SN}$ was shown to be effective not only in reducing Noxl protein levels in the SN (Fig. $7 B, C$ ), but also in reducing oxidative stress (Fig. $8 C$ ) and dopaminergic neuronal death (Fig. $8 A$ ) induced by PQ. Nox1 knockdown induced a significant decrease in the total levels of $\alpha$-synuclein expression (Fig. 9A) after PQ treatment, as well as a decrease in $\alpha$-synuclein aggregation, as demonstrated by a decrease in PK-resistant $\alpha$-synuclein (Fig. 9B). A11 oligomers (Fig. $10 A, B$ ) and ubiquitin (Fig. 10C,D) levels were also decreased, indicating that PQ-mediated $\alpha$-synuclein aggregation is partially regulated by Nox1-derived ROS. These results are in agreement with other studies, which demonstrate that cytoplasmic $\alpha$-synuclein aggregations can be induced by various ROS generators, such as hydroxyl radicals and peroxynitrite (Butterfield and Kanski, 2001; Matsuzaki et al., 2004). These metabolites are strong oxidants that can promote not only nitration but also oxidation of $\alpha$-synuclein, favoring the stabilization of the protein polymer by forming stable cross-linked $\alpha$-synuclein aggregates (Alvarez et al., 1999; Hashimoto et al., 1999; Souza et al., 2000).

In summary, our study provides strong evidence that Nox1 is involved in the mechanism responsible for generation of PQmediated oxidative stress conditions implicated in increased $\alpha$-synuclein expression and aggregation, and dopaminergic neurodegeneration in the $\mathrm{PQ}$-treated rat model of PD. This work also strengthens the possible relationship between oxidative stress and $\alpha$-synuclein pathology in PD, introducing Noxl as a key molecule that could serve as a good therapeutic target for PD and others $\alpha$-synucleinopathies.

\section{References}

Alam ZI, Daniel SE, Lees AJ, Marsden DC, Jenner P, Halliwell B (1997) A generalised increase in protein carbonyls in the brain in Parkinson's but not incidental Lewy body disease. J Neurochem 69:1326-1329.

Alvarez B, Ferrer-Sueta G, Freeman BA, Radi R (1999) Kinetics of peroxynitrite reaction with amino acids and human serum albumin. J Biol Chem 274:842-848.

Beyer K, Domingo-Sàbat M, Ariza A (2009) Molecular pathology of lewy body diseases. Int J Mol Sci 10:724-745.

Brown TP, Rumsby PC, Capleton AC, Rushton L, Levy LS (2006) Pesticides and Parkinson's disease-is there a link? Environ Health Perspect 114: $156-164$.

Butterfield DA, Kanski J (2001) Brain protein oxidation in age-related neu- rodegenerative disorders that are associated with aggregated proteins. Mech Ageing Dev 122:945-962.

Chartier-Harlin MC, Kachergus J, Roumier C, Mouroux V, Douay X, Lincoln S, Levecque C, Larvor L, Andrieux J, Hulihan M, Waucquier N, Defebvre L, Amouyel P, Farrer M, Destée A (2004) Alpha-synuclein locus duplication as a cause of familial Parkinson's disease. Lancet 364:1167-1169.

Choi DH, Kim YJ, Kim YG, Joh TH, Beal MF, Kim YS (2011) Role of matrix metalloproteinase 3-mediated alpha-synuclein cleavage in dopaminergic cell death. J Biol Chem 286:14168-14177.

Choi DH, Cristóvão AC, Guhathakurta S, Lee J, Joh TH, Beal MF, Kim YS (2012) NADPH oxidase 1-mediated oxidative stress leads to dopamine neuron death in Parkinson's disease. Antioxid Redox Signal 16:1033-1045.

Clough RL, Stefanis L (2007) A novel pathway for transcriptional regulation of alpha-synuclein. FASEB J 21:596-607.

Clough RL, Dermentzaki G, Stefanis L (2009) Functional dissection of the alpha-synuclein promoter: transcriptional regulation by ZSCAN21 and ZNF219. J Neurochem 110:1479-1490.

Clough RL, Dermentzaki G, Haritou M, Petsakou A, Stefanis L (2011) Regulation of alpha-synuclein expression in cultured cortical neurons. J Neurochem 117:275-285.

Cookson MR (2009) alpha-Synuclein and neuronal cell death. Mol Neurodegener 4:9.

Cristóvão AC, Choi DH, Baltazar G, Beal MF, Kim YS (2009) The role of NADPH oxidase 1-derived reactive oxygen species in paraquat-mediated dopaminergic cell death. Antioxid Redox Signal 11:2105-2118.

Dexter DT, Carter CJ, Wells FR, Javoy-Agid F, Agid Y, Lees A, Jenner P, Marsden CD (1989) Basal lipid peroxidation in substantia nigra is increased in Parkinson's disease. J Neurochem 52:381-389.

Dexter DT, Holley AE, Flitter WD, Slater TF, Wells FR, Daniel SE, Lees AJ, Jenner P, Marsden CD (1994) Increased levels of lipid hydroperoxides in the parkinsonian substantia nigra: an HPLC and ESR study. Mov Disord 9:92-97.

Donato R, Miljan EA, Hines SJ, Aouabdi S, Pollock K, Patel S, Edwards FA, Sinden JD (2007) Differential development of neuronal physiological responsiveness in two human neural stem cell lines. BMC Neurosci 8:36.

Gatto NM, Rhodes SL, Manthripragada AD, Bronstein J, Cockburn M, Farrer M, Ritz B (2010) alpha-Synuclein gene may interact with environmental factors in increasing risk of Parkinson's disease. Neuroepidemiology 35: 191-195.

Hardy J, Lewis P, Revesz T, Lees A, Paisan-Ruiz C (2009) The genetics of Parkinson's syndromes: a critical review. Curr Opin Genet Dev 19:254265.

Harper SQ, Staber PD, He X, Eliason SL, Martins IH, Mao Q, Yang L, Kotin RM, Paulson HL, Davidson BL (2005) RNA interference improves motor and neuropathological abnormalities in a Huntington's disease mouse model. Proc Natl Acad Sci U S A 102:5820-5825.

Harraz MM, Marden JJ, Zhou W, Zhang Y, Williams A, Sharov VS, Nelson K, Luo M, Paulson H, Schöneich C, Engelhardt JF (2008) SOD1 mutations disrupt redox-sensitive Rac regulation of NADPH oxidase in a familial ALS model. J Clin Invest 118:659-670

Hashimoto M, Hsu LJ, Xia Y, Takeda A, Sisk A, Sundsmo M, Masliah E (1999) Oxidative stress induces amyloid-like aggregate formation of NACP/alpha-synuclein in vitro. Neuroreport 10:717-721.

Javoy F, Sotelo C, Herbet A, Agid Y (1976) Specificity of dopaminergic neuronal degeneration induced by intracerebral injection of 6-hydroxydopamine in the nigrostriatal dopamine system. Brain Res 102:201-215.

Krishnan S, Chi EY, Wood SJ, Kendrick BS, Li C, Garzon-Rodriguez W, Wypych J, Randolph TW, Narhi LO, Biere AL, Citron M, Carpenter JF (2003) Oxidative dimer formation is the critical rate-limiting step for Parkinson's disease alpha-synuclein fibrillogenesis. Biochemistry 42 : 829-837.

Krüger R, Kuhn W, Müller T, Woitalla D, Graeber M, Kösel S, Przuntek H, Epplen JT, Schöls L, Riess O (1998) Ala30Pro mutation in the gene encoding alpha-synuclein in Parkinson's disease. Nat Genet 18:106-108.

Manning-Bog AB, McCormack AL, Li J, Uversky VN, Fink AL, Di Monte DA (2002) The herbicide paraquat causes up-regulation and aggregation of alpha-synuclein in mice: paraquat and alpha-synuclein. J Biol Chem 277: 1641-1644

Matsuzaki M, Hasegawa T, Takeda A, Kikuchi A, Furukawa K, Kato Y, Itoyama Y (2004) Histochemical features of stress-induced aggregates in alpha-synuclein overexpressing cells. Brain Res 1004:83-90.

McCormack AL, Atienza JG, Johnston LC, Andersen JK, Vu S, Di Monte DA 
(2005) Role of oxidative stress in paraquat-induced dopaminergic cell degeneration. J Neurochem 93:1030-1037.

Miller RL, James-Kracke M, Sun GY, Sun AY (2009) Oxidative and inflammatory pathways in Parkinson's disease. Neurochem Res 34:55-65.

Neumann M, Kahle PJ, Giasson BI, Ozmen L, Borroni E, Spooren W, Müller V, Odoy S, Fujiwara H, Hasegawa M, Iwatsubo T, Trojanowski JQ, Kretzschmar HA, Haass C (2002) Misfolded proteinase K-resistant hyperphosphorylated alpha-synuclein in aged transgenic mice with locomotor deterioration and in human alpha-synucleinopathies. J Clin Invest 110:1429-1439.

Nuber S, Petrasch-Parwez E, Winner B, Winkler J, von Hörsten S, Schmidt T, Boy J, Kuhn M, Nguyen HP, Teismann P, Schulz JB, Neumann M, Pichler BJ, Reischl G, Holzmann C, Schmitt I, Bornemann A, Kuhn W, Zimmermann F, Servadio A, et al. (2008) Neurodegeneration and motor dysfunction in a conditional model of Parkinson's disease. J Neurosci 28:2471-2484.

Polymeropoulos MH, Lavedan C, Leroy E, Ide SE, Dehejia A, Dutra A, Pike B, Root H, Rubenstein J, Boyer R, Stenroos ES, Chandrasekharappa S, Athanassiadou A, Papapetropoulos T, Johnson WG, Lazzarini AM, Duvoisin RC, Di Iorio G, Golbe LI, Nussbaum RL (1997) Mutation in the alphasynuclein gene identified in families with Parkinson's disease. Science 276:2045-2047.

Singleton AB, Farrer M, Johnson J, Singleton A, Hague S, Kachergus J, Hulihan M, Peuralinna T, Dutra A, Nussbaum R, Lincoln S, Crawley A, Hanson M, Maraganore D, Adler C, Cookson MR, Muenter M, Baptista M, Miller D, Blancato J, et al. (2003) alpha-Synuclein locus triplication causes Parkinson's disease. Science 302:841.

Sofic E, Lange KW, Jellinger K, Riederer P (1992) Reduced and oxidized glutathione in the substantia nigra of patients with Parkinson's disease. Neurosci Lett 142:128-130.

Sorce S, Krause KH (2009) NOX enzymes in the central nervous system: from signaling to disease. Antioxid Redox Signal 11:2481-2504.

Souza JM, Giasson BI, Chen Q, Lee VM, Ischiropoulos H (2000) Dityrosine cross-linking promotes formation of stable alpha-synuclein polymers.
Implication of nitrative and oxidative stress in the pathogenesis of neurodegenerative synucleinopathies. J Biol Chem 275:18344-18349.

Terzioglu M, Galter D (2008) Parkinson's disease: genetic versus toxininduced rodent models. FEBS J 275:1384-1391.

Turk PW, Laayoun A, Smith SS, Weitzman SA (1995) DNA adduct 8-hydroxyl-2'-deoxyguanosine (8-hydroxyguanine) affects function of human DNA methyltransferase. Carcinogenesis 16:1253-1255.

Uversky VN, Li J, Fink AL (2001) Pesticides directly accelerate the rate of alpha-synuclein fibril formation: a possible factor in Parkinson's disease. FEBS Lett 500:105-108.

Vekrellis K, Xilouri M, Emmanouilidou E, Rideout HJ, Stefanis L (2011) Pathological roles of alpha-synuclein in neurological disorders. Lancet Neurol 10:1015-1025.

Winner B, Jappelli R, Maji SK, Desplats PA, Boyer L, Aigner S, Hetzer C, Loher T, Vilar M, Campioni S, Tzitzilonis C, Soragni A, Jessberger S, Mira H, Consiglio A, Pham E, Masliah E, Gage FH, Riek R (2011) In vivo demonstration that alpha-synuclein oligomers are toxic. Proc Natl Acad Sci U S A 108:4194-4199.

Wood-Kaczmar A, Gandhi S, Yao Z, Abramov AY, Miljan EA, Keen G, Stanyer L, Hargreaves I, Klupsch K, Deas E, Downward J, Mansfield L, Jat P, Taylor J, Heales S, Duchen MR, Latchman D, Tabrizi SJ, Wood NW (2008) PINK1 is necessary for long term survival and mitochondrial function in human dopaminergic neurons. PloS one 3:e2455.

Zarranz JJ, Alegre J, Gómez-Esteban JC, Lezcano E, Ros R, Ampuero I, Vidal L, Hoenicka J, Rodriguez O, Atarés B, Llorens V, Gomez Tortosa E, del Ser T, Muñoz DG, de Yebenes JG (2004) The new mutation, E46K, of alphasynuclein causes Parkinson and Lewy body dementia. Ann Neurol 55:164-173.

Zawia NH, Lahiri DK, Cardozo-Pelaez F (2009) Epigenetics, oxidative stress, and Alzheimer disease. Free Radic Biol Med 46:1241-1249.

Zhang J, Perry G, Smith MA, Robertson D, Olson SJ, Graham DG, Montine TJ (1999) Parkinson's disease is associated with oxidative damage to cytoplasmic DNA and RNA in substantia nigra neurons. Am J Pathol 154:1423-1429. 